\title{
Bonds with transactions service and optimal Ramsey policy
}

\author{
Yifan $\mathrm{Hu}^{\mathrm{a}}$, Timothy Kam ${ }^{\mathrm{b}, *}$ \\ ${ }^{a}$ Citic Securities International, 26/F Citic Tower, 1 Tim Mei Avenue, Hong Kong, China \\ ${ }^{\mathrm{b}}$ School of Economics, H.W. Arndt Building 25A, Australian National University, ACT 0200, Australia
}

\section{A R T I C L E I N F O}

\section{Article history:}

Received 14 August 2008

Accepted 20 January 2009

Available online 7 February 2009

\section{JEL classification:}

E42

E52

E63

\section{Keywords:}

Optimal fiscal and monetary policy

Sticky prices

Liquid bonds

\begin{abstract}
A B S T R A C T
We introduce a model of government bonds with transactions services into a standard dynamic stochastic general equilibrium sticky-price monetary economy. This additional feature results in an endogenous interest-rate spread and affects equilibrium allocations and inflation by altering the Ramsey planner's sequence of implementability and stickyprice constraints. Qualitatively, the trade-off confronting a planner in sticky-price models shown in recent literature, between using inflation surprise and labor-income tax, is eliminated by the liquid bond channel. We find that the more sticky prices become, the more the optimal fiscal-monetary policy stabilizes prices and also creates less distortionary and less volatile income taxes by taxing the liquidity service of bonds. Quantitatively, we show that the additional tax instrument created by the bond liquidity channel can yield a sizable welfare gain from an economy without this channel.
\end{abstract}

(c) 2009 Elsevier Inc. All rights reserved.

\section{Introduction}

How a government coordinates its macroeconomic policies is an important question and is the subject of ongoing interest in policy circles. In theoretical circles, the benchmark positive framework approaches this issue from the point of view of a Ramsey planner with a consolidated fiscal- and monetary-policy plan. However, recent focus has been on model economies where inflation matters and is costly to society in real terms. In this paper we provide an alternative setup of a sticky-price dynamic stochastic general equilibrium model with Ramsey optimal fiscal and monetary policy where there exists an interest-rate spread between two classes of nominally risk-free bonds (government and private bonds) à la Canzoneri and Diba, 2005. The existence of liquid, interest-bearing government bonds creates a spread between the returns on illiquid private bonds and liquid government bonds that acts as an additional tax instrument. ${ }^{1}$ Canzoneri and Diba (2005) provide one real example that, “... [U].S. Treasury bills clearly facilitate transactions in a number of ways: they serve as collateral in many financial markets, banks hold them to manage the liquidity of their portfolios, and individuals hold them in money-market accounts that offer checking services". We investigate how this new feature alters the equilibrium characterization of the Ramsey allocation, and modifies the trade-off between price stability and income tax stability found in recent papers, such as Schmitt-Grohé and Uribe (2004a) and Siu (2004), on Ramsey optimal policy in sticky-price environments.

\footnotetext{
* Corresponding author. Fax: +612 62151072.

E-mail address: timothy.kam@anu.edu.au (T. Kam).

1 The crucial difference between the bonds here is that government bonds provide some liquidity service. Thus, private agents may want to hold assets in the form of government debt in exchange for their liquidity service although they pay a lower return than the private bond. One can envision that the private sector can also issue liquid assets or bonds (e.g., credit cards, commercial paper and etc.). However, for the sake of clarity and exposition, we assume that there only exist a nominally risk-free private bond that is illiquid and the liquid government bond.
} 
We show that government bond dynamics affect the intertemporal allocations of resources via the Ramsey planner's sequence of "implementability constraints". An implementability constraint is a nutshell constraint for the planner which encodes all private optimal decisions in a competitive equilibrium. More precisely, this unexplored effect of government bond liquidity

(i) creates a wedge between the marginal social value of a current government deficit and private (net) marginal utility of consumption (and thereby how the planner discounts future deficits or surpluses);

(ii) alters intratemporally the money-bond transactions technology constraint; and

(iii) affects current inflation via the labor decisions and hence firms' real marginal cost,

and thus influences the sequence of the planner's implementability constraints. This suggests an avenue for fiscal policy, in terms of government debt with liquidity services (via the interest-rate spread), to alter the trade-offs between a limited number of distorting tax instruments faced by a Ramsey planner who wishes to approximate market completion in a world without real state-contingent assets.

We find that the more sticky prices are in our model economy, the more the optimal Ramsey plan favors price stability but the planner can also afford a less distortionary and less volatile income tax scheme. The latter result is opposite to that of existing literature, for example Schmitt-Grohé and Uribe (2004a) and Siu (2004). This is because in our model the dynamics of liquid government bonds affect the government's sequence of implementability (intertemporal solvency) constraints. Thus the planner uses the interest spread channel which alters the dynamics of liquid government bonds, as a means of satisfying the constraints, in designing its optimal tax and monetary policy plan. In doing so, the planner does not have to rely so much on using distortionary income tax or costly inflation to meet its expected intertemporal solvency constraints. Quantitatively, we show that the additional tax instrument created by the bond liquidity channel can yield a sizable welfare gain from an economy without this channel.

In the earlier literature on optimal fiscal and monetary policy, the analyses were often carried out using competitive flexible-price monetary models without capital, for example, Lucas and Stokey (1983), Calvo and Guidotti (1993), and Chari et al. (1991). The general conclusion was that optimal fiscal-monetary policy entails a volatile and serially uncorrelated inflation rate while labor income tax is smooth. This is because the planner uses surprise inflation as a lump-sum tax on household financial wealth, while minimizing the distortionary effect of labor income tax. Thus real government bonds act as a shock absorber to maintain a constant path for the labor income tax rate.

In the seminal works of Schmitt-Grohe and Uribe (2004a) and Siu (2004), the authors provide a variation on the results found in the optimal fiscal-monetary policy literature. In such economies, inflation is costly in terms of real resources such that the planner has to trade-off between minimizing tax distortions and minimizing costly inflation volatility. On one hand, in order to minimize tax distortions on private work incentives, the planner would like to use unexpected variations in the price level as a means for taxing household wealth, which leads to greater inflation volatility. This is the same effect found in the earlier class of flexible-price competitive economies. On the other, the existence of price adjustment cost affects household welfare via their feasibility constraint. This discourages the planner from trading off unexpected inflation with labor income tax variations, resulting in lower inflation volatility. Schmitt-Grohé and Uribe (2004a) find that the second effect dominates. In other words, for modest degrees of price stickiness, the tension is resolved in the direction in favor of price stability or low inflation volatility. Furthermore, the tax rate on labor is still reasonably smooth or "near random walk", but this tends to be less so, when there is imperfect competition; or even less when there exist sticky prices. Siu (2004) also has very similar conclusions. Siu (2004) specifically reports that under an optimal Ramsey policy, the volatility of inflation decreases while that of the labor tax rate increases as the degree of price stickiness in the economy rises. He also finds that the tax distortion can be smoothed over time. ${ }^{2}$

The new addition in our model is a direct adaptation of Canzoneri and Diba (2005) to a more fully specified environment. Canzoneri and Diba (2005) were concerned with the issue of price level determinacy in a deterministic, flexible-price endowment economy with simple monetary- and fiscal-policy rules. In their economy, fiscal policy can provide a nominal anchor, even when monetary policy does not. Their result arises because government bonds can provide liquidity services and this allows bonds to affect the equilibrium process for inflation. They allow for bonds to enter a cash-in-advanced (CIA) constraint and to act as imperfect substitutes for money. We generalize their assumption to a general equilibrium production economy with costly price adjustment, so that there are meaningful short-run monetary policy trade-offs to consider. Furthermore, we consider optimal policy from the point of view of the benchmark Ramsey planner.

The remainder of the paper is organized as follows. We outline the model primitives in Section 2. We show how a decentralized equilibrium, defined in Section 3, can be supported as a Ramsey planning problem in Section 4. We explain the implications of the liquid-bond feature in the model for Ramsey optimal taxation and monetary policy, in Section 4.1. This will be helpful in interpreting the experimental results in the remainder sections. We parameterize the model and perform some numerical experiments to study the behavior of the various Ramsey equilibria in Section 5. First, we consider in Section 5.1 what the optimal Ramsey plan does in various environments - with and without bond liquidity and/or sticky prices - in

\footnotetext{
${ }^{2}$ The result in Siu (2004) and Schmitt-Grohé and Uribe (2004a), in terms of a near-unit-root feature of optimal income tax, echoes the outcome in Aiyagari et al. (2002). In Aiyagari et al. (2002), the model is perfectly competitive but features incomplete markets where there is only real non-state-contingent government debt.
} 
terms of on and off steady state properties. Second, in Section 5.2 we study the off-steady state equilibria of a model with liquid bonds more closely across various degrees of price stickiness. Third, we check for robustness of this result to various cases of bond liquidity in Section 5.3. Fourth, in Section 5.4, we take the baseline calibration of the model with bond liquidity to deduce what the implied optimal Markovian policy looks like. Fifth, we show numerically how the bond liquidity channel aids optimal policy in quantitative welfare cost terms, in Section 5.5. We conclude in Section 6.

\section{The model}

Consider an economy populated by a continuum of infinitely lived identical households on the closed unit interval $[0,1]$. Let $\mathbb{N}:=\{0,1, \ldots\}$. Each period $t \in \mathbb{N}$, households derives utility from consumption, $c_{t}$, and leisure, $1-h_{t}$ where time endowment is unity and $h_{t}$ is the fraction of time spent working. Households are also monopolistic firms producing differentiated intermediate goods. Fiscal and monetary policy will be determined jointly by a Ramsey planner. We begin by specifying the exogenous stochastic processes in the model.

\subsection{Exogenous stochastic processes}

There are two exogenous forcing processes in the model. These can be interpreted as demand and supply shocks. On the demand side, government spending is a Markov process, where

$$
\ln g_{t}=\left(1-\rho_{g}\right) \ln \bar{g}+\rho_{g} \ln g_{t-1}+u_{g, t} ; \rho_{g} \in[0,1), u_{g, t} \sim \text { i.i.d. }\left(0, \sigma_{g}^{2}\right) .
$$

where $\bar{g}$ is steady state government consumption. On the supply side, economy-wide shocks to production technology is given by the Markov process

$$
\ln z_{t}=\rho_{z} \ln z_{t-1}+u_{z, t} ; \rho_{z} \in[0,1), u_{z, t} \sim \text { i.i.d. }\left(0, \sigma_{z}^{2}\right) .
$$

It is assumed that $\left(g_{t}, z_{t}\right)^{\prime} \in \mathscr{S}$ where $\mathscr{S} \subset \mathbb{R}_{+}^{2}$ is compact.

\subsection{Household-firm problem}

Households own monopolistic firms producing a differentiated intermediate good. We will refer to them from now on as "household-firms". Define $Y_{t}$ as the total final demand for aggregate output, $\widetilde{P}_{t}$ as the firm-specific price charged by each firm, and $P_{t}$ the aggregate price level. Thus the demand for this monopolist's good is $d\left(\widetilde{P}_{t} / P_{t}\right) Y_{t}$, where $d^{\prime}\left(\widetilde{P}_{t} / P_{t}\right)<0, d(1)=1$, and $d^{\prime}(1)<-1$. The household-firm employs labor, $\tilde{h}_{t}$, with a competitive nominal wage $w_{t} P_{t}$, and produces using a technology

$$
d\left(\frac{\widetilde{P}_{t}}{P_{t}}\right) Y_{t}=z_{t} \tilde{h}_{t}
$$

Because each household-firm is monopolistic, it can set $\widetilde{P}_{t}$, and following Rotemberg (1982), we assume it faces a real convex cost of price adjustment

$$
C\left(\frac{\widetilde{P}_{t}}{\widetilde{P}_{t-1}}\right)=\frac{\theta}{2}\left(\frac{\widetilde{P}_{t}}{\widetilde{P}_{t-1}}-\bar{\Pi}\right)^{2}
$$

where $\theta$ will be a parameter governing the degree of price stickiness and $\bar{\Pi} \geqslant 1$ is steady state inflation.

Let $m_{t}=M_{t} / P_{t}$ and $b_{t}=B_{t} / P_{t} \in \mathscr{B} \subset \mathbb{R}_{+}$, respectively, denote real money balances and real government bond holdings determined at the end of period $t$. Define $\Pi_{t}=P_{t} / P_{t-1}$ and $p_{t}=\widetilde{P}_{t} / P_{t}$, respectively, as gross inflation and a firm-specific price relative to the average price level. Let $R_{t}$ be the one-period nominally risk-free gross return on government bond holdings, $b_{t}^{*} \in \mathscr{B}^{*} \subset \mathbb{R}$ be a private bond that pays a nominally risk-free return of $R_{t}^{*}$ in period $t+1$, and $\tau_{t} \in[0,1]$ be the flat tax rate on labor income. The sequence of household budget constraints is given by

$$
c_{t}+m_{t}+b_{t}+b_{t}^{*} \leqslant \frac{m_{t-1}}{\Pi_{t}}+R_{t-1} \frac{b_{t-1}}{\Pi_{t}}+R_{t-1}^{*} \frac{b_{t-1}^{*}}{\Pi_{t}}+\left[p_{t} Y_{t} d\left(p_{t}\right)-w_{t} \tilde{h}_{t}-\frac{\theta}{2}\left(\frac{p_{t}}{p_{t-1}} \Pi_{t}-\bar{\Pi}\right)^{2}\right]+\left(1-\tau_{t}\right) w_{t} h_{t}
$$

for $t=0,1,2, \ldots$. The household's present value of its total expected lifetime utility is

$$
\mathbb{E}_{0} \sum_{t=0}^{\infty} \beta^{t} U\left(c_{t}, h_{t}\right)
$$

where $\mathbb{E}_{0}$ is the mathematical expectations operator, taken over the sequence of functions $U\left(c_{t}, h_{t}\right)$ measurable with respect to the information set generated by $\left\{z_{t}, g_{t}, b_{t}^{*}, b_{t}\right\}$ at time 0 . $U(\cdot)$ satisfies the Inada conditions: $\lim _{c \backslash 0} U_{c}(c, h)=+\infty$ and $\lim _{l \backslash 0} U_{l}(c, h)=+\infty$ where $l:=1-h$. The household maximizes (6) subject to (5) and a cash-in-advance (CIA) constraint:

$$
m_{t}+k\left(b_{t}\right) \geqslant c_{t} .
$$


The transactions service of bonds is reflected in the function $k\left(b_{t}\right)$ which satisfies the following properties, which are similar to Canzoneri and Diba (2005) except for a minor modification to allow for endogenous output determination in our model.

Assumption 1. The function $k\left(b_{t}\right)$ satisfies:

A1 $k\left(b_{t}\right)=0$ for $b_{t} \leqslant 0$;

A2 $k^{\prime}\left(b_{t}\right)>0$ and $k^{\prime \prime}\left(b_{t}\right)<0$ for $b_{t}>0$;

A3 $\lim _{b \backslash 0} k^{\prime}\left(b_{t}\right)<1, \lim _{b /+\infty} k^{\prime}\left(b_{t}\right)=0$ and $\lim _{b /+\infty} k\left(b_{t}\right)<c_{t}$.

Assumption A1 ensures that negative bond holdings do not provide any transactions value so that $b_{t} \in \mathscr{B} \subset \mathbb{R}_{+}$, and A2 ensures that positive government bond holdings provide increasing transactions service, but the marginal transactions service is decreasing. Lastly, A3 ensures that these bonds are never sufficient to fund all consumption purchases. ${ }^{3}$ That is, there will still be positive holdings of money. ${ }^{4}$

Let the Lagrange multiplier on the constraints (7) and (5) be $\mu_{t}$ and $\lambda_{t}$, respectively, and the multiplier on the technology constraint (3), when inserted into (5) be $m c_{t} \lambda_{t}$, where $m c_{t}$ is the real marginal cost of production for a firm. The first-order conditions are

$$
\begin{array}{ll}
c_{t}: & U_{c}\left(c_{t}, h_{t}\right)=\lambda_{t}+\mu_{t} \\
b_{t}^{*}: & \lambda_{t}=\beta R_{t}^{*} \mathbb{E}_{t}\left(\frac{\lambda_{t+1}}{\Pi_{t+1}}\right) \\
b_{t}: & \lambda_{t}=R_{t} \beta \mathbb{E}_{t}\left(\frac{\lambda_{t+1}}{\Pi_{t+1}}\right)+\mu_{t} k^{\prime}\left(b_{t}\right) \\
m_{t}: & \lambda_{t}=\beta \mathbb{E}_{t}\left(\frac{\lambda_{t+1}}{\Pi_{t+1}}\right)+\mu_{t} \\
h_{t}: & U_{h}\left(c_{t}, h_{t}\right)=-\lambda_{t}\left(1-\tau_{t}\right) w_{t} \\
\tilde{h}_{t}: & \frac{w_{t}}{z_{t}}=m c_{t} \\
\widetilde{P}_{t}: & \lambda_{t}\left[Y_{t} d\left(p_{t}\right)+p_{t} Y_{t} d^{\prime}\left(p_{t}\right)-\theta\left(\frac{\Pi_{t} p_{t}}{p_{t-1}}-\bar{\Pi}\right) \frac{\Pi_{t}}{p_{t-1}}-m c_{t} Y_{t} d^{\prime}\left(p_{t}\right)\right]+\beta \mathbb{E}_{t}\left[\lambda_{t+1} \theta\left(\frac{\Pi_{t+1} p_{t+1}}{p_{t}}-\bar{\Pi}\right) \frac{\Pi_{t+1} p_{t+1}}{p_{t}^{2}}\right]=0
\end{array}
$$

for all states and dates $t \in \mathbb{N}$. The last two conditions (14) and (15), respectively, characterize the optimal labor demand by the household-firm and the optimal price-setting condition which depends on expected future prices. These first-order conditions are quite standard, apart from (11).

\subsection{Symmetric pricing equilibrium}

In equilibrium, there is no trade of the private bond. However it can be shown that the interest rate on the private bond must still be positive in equilibrium.

Lemma 1. In equilibrium $b_{t}^{*}=0$ and $R_{t}^{*}>1$.

Proof. Identical households have no desire to borrow or lend to each other on the private asset market so that $b_{t}^{*}=0$ in equilibrium. From the optimality conditions (10) and (12), we have

$$
\mu_{t}=\lambda_{t}\left(\frac{R_{t}^{*}-1}{R_{t}^{*}}\right)
$$

for all states and dates $t \in \mathbb{N}$. By the Inada condition on consumption, it must be that $c_{t}>0$, and along with Assumption 1 , the CIA constraint must bind so that $\mu_{t}>0$, and with optimality such that $\lambda_{t}>0$, for all states and dates $t \in \mathbb{N}$, then (16) implies that $R_{t}^{*}>1$ for all states and dates $t \in \mathbb{N}$.

\footnotetext{
${ }^{3}$ In terms of practical implementation, to ensure the CIA binds at all times and still satisfies positive money holdings, we will assume shocks with small bounded supports, and admit only the parameter $\lim _{b>+\infty} k\left(b_{t}\right)=\phi$ such that for sufficiently large steady state consumption, $\bar{c}>\phi$, consumption $c_{t}$ will almost surely be bounded above $k\left(b_{t}\right)$ for all $t$ and all histories leading up to and including date $t$.

${ }^{4}$ Alternatively we could have modeled the CIA constraint as

$$
m_{t}+k\left(b_{t}\right) c_{t} \geqslant c_{t}
$$

where $k$ still satisfies Assumption 1. This would be closer to the CIA constraint in the endowment economy of Canzoneri and Diba (2005), where $c_{t}=y=1$. In this case, $m_{t}$ will be strictly positive since $c_{t}$ is nonnegative under the Inada conditions, and $k\left(b_{t}\right) \in(0,1)$. However, this assumption creates additional nonlinearities in the optimality conditions with respect to liquid bonds for households and the planner, without affording much difference in the qualitative implications of the model.
} 
Also, in a symmetric equilibrium, all household-firms charge the same price, so that $p_{t}=1$. That is, all households will charge the same price as the average price, or $\widetilde{P}_{t}=P_{t}$, for all $t$. Given the same production technology and competitive wage rate, it must be that the amount of labor supplied by each household equals its demand in its production such that $h_{t}=\tilde{h}_{t}$. The demand for each monopolist's good is $d\left(p_{t}\right) Y_{t}$ so that the elasticity of demand for each good is $\epsilon\left(p_{t}\right)=d^{\prime}\left(p_{t}\right) p_{t} Y_{t} / d\left(p_{t}\right) Y_{t}$.

In a symmetric equilibrium, $p_{t}=1$ so that under our assumption that $d(1)=1$, we get the elasticity of demand faced by each household-firm is constant, $\eta \equiv d^{\prime}(1)<-1$. Since the marginal revenue for each monopolist is $\left[1+\epsilon\left(p_{t}\right)\right] d\left(p_{t}\right) Y_{t}$, in the symmetric equilibrium, marginal revenue for all monopolists becomes $(1+\eta) Y_{t}$. The optimal pricing condition (15), together with the fact that in a symmetric equilibrium, $Y_{t}=z_{t} h_{t}$ and also using (14), can be expressed as

$$
\left(\Pi_{t}-\bar{\Pi}\right) \Pi_{t}=\beta \mathbb{E}_{t}\left[\frac{\lambda_{t+1}}{\lambda_{t}}\left(\Pi_{t+1}-\bar{\Pi}\right) \Pi_{t+1}\right]+\frac{\eta z_{t} h_{t}}{\theta}\left[\frac{1+\eta}{\eta}-\frac{w_{t}}{z_{t}}\right] .
$$

This is an expectations-augmented Phillips curve, which says that time-t inflation depends on the contemporaneous gap between real marginal cost and steady state real marginal cost, $\eta^{-1}(1+\eta)$, and expected discounted next-period inflation. Also, the greater is the cost of prices adjustment, $\theta \rightarrow \infty$, the closer is expected discounted next-period inflation to current inflation. That is, prices are expected not to change very much the more costly is price adjustment. The greater is the elasticity of demand, $\eta \rightarrow-\infty$, the more positive and sensitive is the response of current inflation to real marginal cost (limiting case of perfect competition).

\subsection{Resource constraint}

The resource constraint is given by

$$
z_{t} h_{t}=c_{t}+g_{t}+\frac{\theta}{2}\left(\Pi_{t}-\bar{\Pi}\right)^{2}
$$

which is the market clearing condition for private and public consumption goods, where some of that produced resources is dissipated in terms of a price adjustment cost.

\subsection{Government budget constraint}

The sequence of government budget constraints is

$$
M_{t}+B_{t}+\tau_{t} P_{t} w_{t} h_{t}=M_{t-1}+R_{t-1} B_{t-1}+P_{t} g_{t} .
$$

This says that government spending and the payment of public debt with interest, is financed with either the issue of new money, new debt or income tax receipts. We can re-write this in real terms as

$$
m_{t}+b_{t}+\tau_{t} w_{t} h_{t}=\frac{m_{t-1}}{\Pi_{t}}+\frac{R_{t-1} b_{t-1}}{\Pi_{t}}+g_{t}
$$

for $t \in \mathbb{N}$. Notice that with higher inflation, the government can relax the one-period government budget constraint by lowering the real liability of money holding $m_{t-1} / \Pi_{t}$. This also makes the real gross return on government bonds, $R_{t-1} / \Pi_{t}$, depend on the state of inflation.

\section{Decentralized equilibrium}

The following defines the competitive or decentralized equilibrium for a given feasible policy rule.

Definition 1. Given policy rule $\left\{\tau_{t}, R_{t}, R_{t}^{*}\right\}_{t=0}^{\infty}$, a decentralized equilibrium is a sequence of bounded allocation functions $\left\{c_{t}, h_{t}, m_{t}, w_{t}, \Pi_{t}, m c_{t}, b_{t}\right\}_{t=0}^{\infty}$ respecting the optimality conditions (9), (10), (11), (12), (13), (14) and (17), satisfying the feasibility constraints (18) and (19) and the transversality condition

$$
\lim _{s \rightarrow \infty} \mathbb{E}_{t}\left(\prod_{i=0}^{s} R_{t+i}^{-1}\right)\left(R_{t+s} B_{t+s}+M_{t+s}\right)=0,
$$

for given stochastic processes (1) and (2).

\section{Ramsey problem}

We cast the fiscal and monetary policy problem in terms of a Ramsey planning problem which implements a decentralized equilibrium. First we characterize the equilibrium using the primal approach as in Atkinson and Stiglitz (1980), Lucas and Stokey (1983), and Chari et al. (1995), which characterizes the equilibrium in terms of allocations (and the inflation rate) as far as possible. This is done so that we can show, in a condensed way, how the introduction of liquid government bonds, $b_{t}$, 
can alter the Ramsey equilibrium allocations. In order to analyze the qualitative behavior of these dynamics, we will characterize and solve the Ramsey problem using the dual approach, as set out in Appendix B.

The following proposition shows that the equilibrium plan under such a Ramsey planner also satisfies the condition of a decentralized equilibrium in Definition 1.

Proposition 1. The plan $\left\{c_{t}, h_{t}, \Pi_{t}, m c_{t}, b_{t}, R_{t}^{*}\right\}_{t=0}^{\infty}$ respecting the resource constraint (18), the sequence of government budget constraints:

$$
c_{t}-k\left(b_{t}\right)+b_{t}+\left(m c_{t} z_{t}+\frac{U_{h}\left(c_{t}, h_{t}\right)}{U_{c}\left(c_{t}, h_{t}\right) /\left(2-R_{t}^{*-1}\right)}\right) h_{t}=\frac{c_{t-1}-k\left(b_{t-1}\right)}{\Pi_{t}}+\frac{\left[R_{t-1}^{*}-\left(R_{t-1}^{*}-1\right) k^{\prime}\left(b_{t-1}\right)\right] b_{t-1}}{\Pi_{t}}+g_{t}
$$

for $t \geqslant 1$ and

$$
c_{0}-k\left(b_{0}\right)+b_{0}+\left(m c_{0} z_{0}+\frac{U_{h}\left(c_{0}, h_{0}\right)}{U_{c}\left(c_{0}, h_{0}\right) /\left(2-R_{0}^{*-1}\right)}\right) h_{0}=\frac{M_{t-1}+R_{-1} B_{-1}}{P_{-1} \Pi_{0}}+g_{0}
$$

the expectational Phillips curve

$$
\left(\Pi_{t}-\bar{\Pi}\right) \Pi_{t}=\beta \mathbb{E}_{t}\left[\frac{U_{c}\left(c_{t+1}, h_{t+1}\right) /\left(2-R_{t+1}^{*-1}\right)}{U_{c}\left(c_{t}, h_{t}\right) /\left(2-R_{t}^{*-1}\right)}\left(\Pi_{t+1}-\bar{\Pi}\right) \Pi_{t+1}\right]+\frac{\eta z_{t} h_{t}}{\theta}\left[\frac{1+\eta}{\eta}-m c_{t}\right]
$$

and the sequence of present value implementability constraints,

$$
\begin{aligned}
\mathbb{E}_{t} \sum_{s=0}^{\infty} \frac{\beta^{s}}{\Delta_{t, t+s}} \frac{U_{c}\left(c_{t+s}, h_{t+s}\right)}{\left(2-R_{t+1}^{*-1}\right)}\left\{\left[1+\frac{\left(R_{t+s}^{*}-1\right)\left(1-k^{\prime}\left(b_{t+s}\right)\right)}{R_{t+s}^{*}-\left(R_{t+s}^{*}-1\right) k^{\prime}\left(b_{t+s}\right)}\right] c_{t+s}+\left(m c_{t+s}-1\right) z_{t+s} h_{t+s} .\right. \\
\left.-\frac{\left(R_{t+s}^{*}-1\right)\left(1-k^{\prime}\left(b_{t+s}\right)\right)}{R_{t+s}^{*}-\left(R_{t+s}^{*}-1\right) k^{\prime}\left(b_{t+s}\right)} k\left(b_{t+s}\right)+\frac{U_{h}\left(c_{t+s}, h_{t+s}\right) h_{t+s}}{U_{c}\left(c_{t+s}, h_{t+s}\right) /\left(2-R_{t+1}^{*-1}\right)}\right\} \\
=\frac{U_{c}\left(c_{t}, h_{t}\right)}{\left(2-R_{t}^{*-1}\right)}\left[\frac{R_{t-1}^{*}-\left(R_{t-1}^{*}-1\right) k^{\prime}\left(b_{t-1}\right) b_{t-1}+c_{t-1}-k\left(b_{t-1}\right)}{\Pi_{t}}\right]
\end{aligned}
$$

where $\Delta_{t, t+s}=\prod_{i=1}^{s}\left[1-\left(1-R_{t+i-1}^{*-1}\right) k^{\prime}\left(b_{t+i-1}\right)\right]$, for all states and $t=0,1,2, \ldots$, and given initial conditions $\left(R_{-1} B_{-1}+M_{-1}\right) / P_{-1}$ also satisfies the decentralized equilibrium in Definition 1.

Proof. See Appendix A.

The LHS of (24) is the expected present value of the stochastic stream of utility value of the government's real budget surpluses, which takes into account private agents' optimal plans given the government's strategy. However, this is augmented by: (a) monopolistic competitive distortions; and (b) private demand for liquidity, which would reduce to similar implementability contraints for flexible-price economies if $m c_{t+s}=0, \forall t, s \geqslant 0$. The RHS is the utility value of existing government budget deficit at the beginning of time $t \geqslant 0$.

\subsection{Liquid-bond implications for optimal policy}

We are now in a position to identify the role of government bond liquidity in altering the standard Ramsey planner's solution as encapsulated in Proposition 1. To make the analysis more interpretable, one can think of the planner's policy as a plan in terms of policy instruments. This plan is captured by the sequence of state-contingent policy functions $\left\{R_{t}^{*}, R_{t}, \tau_{t}\right\}_{t=0}^{\infty}$.

The first interest rate $R_{t}^{*}$ can be thought as monetary policy pinning down the pricing kernel with respect to the private bond, $b_{t}^{*}$, which then pins down optimal private consumption in the Euler equation (10). Given $\left\{R_{t}^{*}\right\}_{t=0}^{\infty}$, combining the marginal utility of consumption (9) and (10), real money demand optimality (12), and optimal labor supply decision (13), we have:

$$
-\frac{U_{h}\left(c_{t}, h_{t}\right)}{U_{c}\left(c_{t}, h_{t}\right)}=\left(1-\tau_{t}\right) w_{t}\left(\frac{R_{t}^{*}}{2 R_{t}^{*}-1}\right)
$$

so that the planner affects the consumption-leisure margin by setting income tax policy $\left\{\tau_{t}\right\}_{t=0}^{\infty}$ for given real wage rate $w_{t}$. Eq. (25) is the usual consumption-leisure intratemporal condition with the qualification that with money demand through the CIA constraint, the opportunity cost of money, $R_{t}^{*}$ affects the marginal utility of consumption via the marginal cost of liquidity holding, $\mu_{t}$. Consider now the policy instrument $R_{t}$. Combining (10)-(12), we can express the optimal demand for government bonds as

$$
k^{\prime}\left(b_{t}\right)=\frac{R_{t}^{*}-R_{t}}{R_{t}^{*}-1}
$$


At the optimum, the household will demand government bonds up to the point where the marginal transactions value of such bonds are equal to the marginal opportunity cost of holding government bonds, relative to the private bond which pays a return of $R_{t}^{*}$. Notice that as long as $b_{t}>0$ it must be that, $R_{t}^{*}-R_{t}>0$ since $k^{\prime}\left(b_{t}\right)>0$. Thus, as long as the government issues bonds with transactions value for private agents, there will exist an interest-rate spread in the model. ${ }^{5}$

We next explain in details the three channels, outlined in Section 1, through which government bonds with transactions services affect the planner's optimal policy plan.

\subsubsection{The intertemporal effect of $b_{t}$ on the implementability constraints}

The key feature to note is that $\left\{b_{t+s}\right\}_{s=0}^{\infty}$ appears in the implementability constraint (24) and this has a different implication for the optimal policy plan. This is not the case in conventional models where bonds do not provide transactions services.

Proposition 2. When $k(b)>0$, government bond liquidity creates an endogenous wedge between the marginal social value of a current government deficit and the household's private net marginal utility of consumption, $U_{c}\left(c_{t}, h_{t}\right)-\mu_{t}$. Conversely, if $k(b)=0$, then $\lambda_{t}^{s}=U_{c}\left(c_{t}, h_{t}\right)-\mu_{t}$, for all possible histories.

Proof. Consider rewriting the Ramsey planner's problem as the dual problem in Appendix B. The multiplier $\lambda_{t}^{s}$ is the statecontingent Lagrange multiplier on the sequence of government budget constraints. If $k\left(b_{t}\right)=0$ for all dates and states, then the first-order condition derived in Appendix B,

$$
\lambda_{t}^{s}\left[1-k^{\prime}\left(b_{t}\right)\right]-\beta \mathbb{E}_{t} \frac{\lambda_{t+1}^{s}}{\prod_{t+1}}\left\{\left[R_{t}^{*}-\left(R_{t}^{*}-1\right)\left(k^{\prime}\left(b_{t}\right)+b_{t} k^{\prime \prime}\left(b_{t}\right)\right)\right]+k^{\prime}\left(b_{t}\right)\right\}=0,
$$

reduces to

$$
\lambda_{t}^{s}=\beta R_{t}^{*} \mathbb{E}_{t} \frac{\lambda_{t+1}^{s}}{\prod_{t+1}} .
$$

which is exactly the same Euler equation as the representative household's in (10) for all dates and states. Therefore, $\lambda_{t}^{s}=\lambda_{t}=U_{c}\left(c_{t}, h_{t}\right)-\mu_{t}$ for all histories.

Where $k(b)=0$ in Proposition 2 is a typical feature of standard Ramsey allocations in economies with (see Schmitt-Grohé and Uribe, 2004a) and without (see Chari et al., 1995) sticky-price distortions. This feature no longer holds when one-period government bonds can provide liquidity or transactions services. Intuitively, it is this wedge that affects how the planner discounts future deficits or surpluses.

\subsubsection{The intratemporal effect of $b_{t}$ on the implementability constraints}

A consequence of liquid bond demand is that real money demand is now affected by the process of government bonds, $b_{t}$, directly. This can be seen by combining the CIA constraint (7) with (9) to yield real money demand as $m_{t}=U_{c}^{-1}\left(\lambda_{t}+\mu_{t}\right)-k\left(b_{t}\right)$ and $\lambda_{t}$ and $\mu_{t}$ are pinned down by (10)-(12) which explicitly involve the demand for government bonds $k^{\prime}\left(b_{t}\right)$. Hence, there is an intratemporal effect of the policy spread $R_{t}^{*}-R_{t}$, or equivalently, $b_{t}$, that determines the distribution of household liquidity holdings between money and government bonds.

\subsubsection{The intertemporal effect of $b_{t}$ on the pricing and implementability constraints}

Further, government bonds affect optimal inflation dynamics (15) through the real marginal cost of production, $m c_{t}$, and this comes directly from its immediate effect on the marginal value of wealth $\lambda_{t}$ in (11) and hence optimal labor supply and demand, (13) and (14). This has a direct effect on the Phillips curve constraint for the planner (23) and thus gross inflation $\Pi_{t}$.

Overall, the planner in a standard Ramsey model would faces a problem of trading off the reduction of current liabilities by surprise inflation (RHS of (24)) with using labor income tax (last term on the LHS of (24)). This is qualified by the additional Phillips curve constraint if the economy has a sticky-price feature, as shown in Schmitt-Grohé and Uribe (2004a). However, in this model, the trade-off is further modified explicitly by the path of $b_{t}$ via the three channels described above, and this is clearly seen on the LHS of the implementability constraint (24).

Thus, the existence of liquid $b_{t}$ allows the planner to exploit the spread, $R_{t}^{*}-R_{t}$, and therefore the path of $b_{t}$ in order to satisfy its sequence of implementability constraints in (24) and sticky-price constraints (23) in return for smoothing labor income tax across states and dates and also maintaining stability in costly inflation, under the Ramsey optimal plan. This will alter some of the trade-off between price stability and across-state and across-time labor tax smoothing result found by Siu (2004) and Schmitt-Grohé and Uribe (2004a). While it is not possible to show analytically how liquid government bonds alleviate these constraints in the model, we can show these results numerically in Section 5.

\footnotetext{
5 There are many empirical studies, notably Weil (1989), Giovannini and Labadie (1991), Bansal and Coleman (1996), and Canzoneri et al. (2007), that find a sizeable spread between the average return on equity and the return on treasury bills. In our model, care has to be taken to interpret the interest-rate spread literally as an "equity premium". As Canzoneri and Diba (2005) suggest, one might attempt to measure our return on the illiquid private bond, $R^{*}$, using consumption and price data on our household's Euler equation. Further, one can take the return on liquid government bonds, $R$, as that for a three-month $T$-bill. In that instance, our notion of an interest-rate spread, $R^{*}-R$, should have a magnitude that is close to what is observed as the equity premium.
} 


\section{Properties of the ramsey equilibrium}

In this section, we present numerical solutions and examples of the Ramsey equilibrium, in order to study the qualitative behavior of the model. First, we consider how the optimal Ramsey program behaves in environments with and without sticky prices and/or liquid bonds, using a baseline calibration. Second, we examine the behavior of the Ramsey plan within successively more sticky price environments, when we allow for liquid government bonds. Third, we investigate further the role that bond liquidity plays, by repeating the previous experiment across different degrees of bond liquidity.

In order to study the qualitative features of the model, we have to resort to numerical examples. To do so, we impose functional forms on the model's primitives and parameterize the model using estimates provided in the literature elsewhere. We assume the period utility of the representative household to be $U(c, h)=\ln c+\delta \ln (1-h)$. A bonds transactions service function, which satisfies Assumption 1, is $k(b)=\phi\left(1-e^{-\frac{b}{c}}\right)$ where $\phi \leqslant \bar{c}$ and $\bar{c}$ is steady state consumption. This functional form is similar to that used by Canzoneri and Diba (2005) in their numerical example.

The baseline sticky-price-liquid-bond economy (denoted later as SP) is parameterized to annual post-war US data. The parameterization is summarized in Table 1 . The calibration of $\beta$, given steady state inflation $\bar{\Pi}=1.042$, ensures that steady state nominal return on the private bond is $R^{*}=1.09$. Given the share of government debt in GDP of about 44 per cent per annum, we can set $\phi$ to ensure that the interest-rate spread, $R^{*}-R$ in steady state is about $5 \%$, following the findings of Bansal and Coleman (1996). The parameter $\delta$ is solved endogenously using the government budget constraint at steady state, and is consistent with a fraction of hours worked, $h=0.2$. The details of pinning down the values of $\phi$ and $\delta$ can be found in Appendix C. The rest of the parameters follow the calibration of Schmitt-Grohé and Uribe (2004a). We employ a secondorder accurate perturbation method by Schmitt-Grohé and Uribe (2004b) to solve for the optimal state transition and policy functions around the non-stochastic steady state.

\subsection{Equilibrium comparisons}

We will focus on comparing alternative model settings and assessing the models' qualitative tax properties using the baseline calibration in Table 1, unless otherwise stated. This exercise is reported in Table 2 . The four settings we consider here are:

(i) Model FP*: Flexible-prices, $\theta=0$, where government bonds are not liquid, $\phi=0$.

(ii) Model SP*: Sticky-prices, $\theta=17.5 / 4$, where government bonds are not liquid, $\phi=0$.

(iii) Model FP: Flexible-prices, $\theta=0$, and government bonds provide liquidity, $\phi=0.149$.

(iv) Model SP: Sticky-prices, $\theta=17.5 / 4$, and government bonds provide liquidity, $\phi=0.149$.

We do not report the case where there are flexible-prices and perfectly competitive markets since the results are well known in the literature, as summarized by Chari et al. (1991). We focus only on the role of liquid bonds and its implications for optimal policy in more recent model economies with non-competitive markets. It should also be noted that, we do make claims as to the quantitative relevance of the results with respect to actual data. Furthermore, since we have a different way of introducing money and bonds compared to similar existing papers, our numerical results will not exactly match those of, for example, Schmitt-Grohé and Uribe (2004a).

\subsubsection{Steady state tax properties}

Consider the steady state or unconditional mean properties reported in Table 2 . When government bonds do not provide liquidity ( $\mathrm{FP}^{*}$ and $\left.\mathrm{SP}^{*}\right), \phi=0$, the instrument $R_{t}$ becomes redundant. This is obvious from the identical stochastic discount factor in (10) and (11), so that $R_{t}=R_{t}^{*}$ for all sample paths. More interestingly, when $\phi \neq 0$, the steady state or mean spread

Table 1

Baseline full model (SP) parameterization.

\begin{tabular}{lll}
\hline Parameter & Value & Description \\
\hline$\beta$ & 0.956 & Subjective discount factor \\
$s_{g}$ & 0.2 & Share of government consumption in GDP \\
$\bar{\Pi}$ & 1.042 & Gross inflation rate \\
$\bar{z}$ & 1 & Steady state level of technology \\
$\delta$ & 3.017 & Labor supply parameter \\
$\phi$ & 0.149 & Bond substitutability parameter \\
$b / z h$ & 0.44 & Share of government debt in GDP \\
$\theta$ & $17.5 / 4$ & Degree of price stickiness \\
$\eta$ & -6 & Elasticity of demand \\
$\rho_{z}$ & 0.82 & Autocorrelation of technology \\
$\sigma_{z}$ & 0.0229 & Standard deviation of technology shock \\
$\rho_{g}$ & 0.9 & Autocorrelation of government spending \\
$\sigma_{g}$ & 0.0302 & Standard deviation of government spending shock \\
\hline
\end{tabular}


Table 2

Tax rate properties of various economies.

\begin{tabular}{|c|c|c|c|c|}
\hline Economies & $R^{*}$ & $R$ & $\Pi$ & $\tau$ \\
\hline & \multicolumn{4}{|c|}{ Unconditional mean } \\
\hline $\mathrm{FP}^{*}(\phi=\theta=0)$ & 1.014 & - & 0.969 & 0.427 \\
\hline $\mathrm{SP}^{*}(\phi=0, \theta=17.5 / 4)$ & 1.090 & - & 1.040 & 0.341 \\
\hline $\mathrm{FP}(\theta=0)$ & 1.063 & 1.000 & 1.017 & 0.390 \\
\hline \multirow[t]{2}{*}{$\mathrm{SP}(\phi=0.149, \theta=17.5 / 4)$} & 1.090 & 1.018 & 1.042 & 0.370 \\
\hline & \multicolumn{4}{|c|}{ Percentage standard deviation } \\
\hline $\mathrm{FP}^{*}(\phi=\theta=0)$ & 0.532 & - & 0.532 & 0.893 \\
\hline $\mathrm{SP}^{*}(\phi=0, \theta=17.5 / 4)$ & 0.009 & - & 0.007 & 0.160 \\
\hline $\mathrm{FP}(\phi=0.149, \theta=0)$ & 0.113 & 0.069 & 0.119 & 0.229 \\
\hline \multirow[t]{2}{*}{$\mathrm{SP}(\phi=0.149, \theta=17.5 / 4)$} & 0.005 & 0.037 & 0.001 & 0.091 \\
\hline & \multicolumn{4}{|c|}{ Autocorrelation } \\
\hline $\mathrm{FP}^{*}(\phi=\theta=0)$ & 0.960 & - & 0.963 & 0.891 \\
\hline $\mathrm{SP}^{*}(\phi=0, \theta=17.5 / 4)$ & 0.783 & - & 0.997 & 0.929 \\
\hline $\mathrm{FP}(\phi=0.149, \theta=0)$ & 0.908 & 0.916 & 0.759 & 0.153 \\
\hline $\mathrm{SP}(\phi=0.149, \theta=17.5 / 4)$ & 0.684 & 0.958 & 0.181 & 0.777 \\
\hline
\end{tabular}

Notes:

1. Statistics of $H=500$ simulations of length $T=100$.

2. The first 500 periods of time series were discarded.

$R^{*}-R$ is higher under sticky prices (SP) than under flexible prices (FP). Also, gross inflation is higher under SP than FP. Labor income tax rate is almost identical across FP and SP.

An intuition for these steady state results is that under SP, the planner can use inflation as a tax on monopolistically competitive profits. As shown by Schmitt-Grohé and Uribe (2004a) the more costly it is to change prices, the more, in their case, is the inflation rate closer zero, so that the nominal interest rate deviates more from the Friedman rule of zero nominal interest. In our case, we have normalized the steady state inflation rate to 4.2 per cent per annum to be consistent with post-war US data. So the analogous result we have is that in the SP economy the planner pushes the inflation rate to its "zero" at 4.2 per cent, compared to the more deflated level of $1.7 \%$ in the FP economy. There is also a larger tax on liquidity as measured by both $R$ and $R^{*}$ when moving from FP to SP. This is our equivalent of the increased deviations from the Friedman rule when moving from FP to SP.

We show this further in Fig. 1 where we plot the results of the asymptotic unconditional mean of the key variables over different values for the degree of price stickiness, $\theta$. (We leave a similar analysis on the model's properties with respect to fluctuations to Section 5.2 later.) The difference here is we focus only on sticky-price economies. It can be seen that as $\theta$ increases, the interest-rate spread rises. Inflation tax increases toward its steady state, while government bond holdings and income tax rate $\tau$ falls with $\theta$. As prices become more sticky, the planner is more concerned about the resource cost of inflation deviation. The monetary policy aspect of the planner's policy involves further deviation from the Friedman rule by increasing $R^{*}$. However, the fiscal policy aspect of the optimal Ramsey plan involves lowering $R$ relatively to $R^{*}$ so as to create a larger spread in $R^{*}-R$ and thereby altering the level of liquid bond holdings. As suggested earlier in Section 4.1, this only distorts the distribution of liquidity holdings between money and government bonds, but by lowering the level of government bonds the planner can adjust its sequence of implementability constraints (24) by lowering average income tax and instead increasing the tax on liquidity services.

The intuition for this is that increasing deviations from the Friedman rule is called for in order to indirectly tax monopoly profits, but this results in a larger tax on money. To offset this effect on money holdings, the planner engineers a higher tax on liquidity holdings in terms of the government bond, by increasing the spread in $R^{*}-R$, which on the demand side of the cash-only goods market, is also used to purchase cash consumption goods. Also the planner must deliver a lower tax on labor so that there is more production of the consumption good. Thus, the optimal plan causes the quantity of liquid government bonds to fall and money holdings to rise (Fig. 1b). With increasing spread in $R^{*}-R$, households shift from holding government bonds to holding more money for purchasing within-period cash consumption goods.

\subsubsection{Tax volatility and persistence properties}

Table 2 also reports the volatility (second panel) and persistence (bottom panel) properties of the four comparative economies. It can be seen that the Ramsey optimal policy involves relatively less volatile inflation when there is a sticky-price cost to inflation (SP and $\mathrm{SP}^{*}$ ) compared to when inflation volatility is costless (FP and FP*). In the flexible-price economy (FP) without the interest-rate spread, the planner uses ex-post inflation volatility to induce greater variability of ex-post real return on government debt so that government debt act as a shock absorber in order to maintain smoother taxes acrossstates (volatility) and dates (persistence).

The use of ex-post inflation volatility becomes less vital to the planner when there exists bond liquidity (FP ${ }^{*}$ ) so that inflation volatilities are lower relative to FP, since now an optimal Ramsey plan can induce state-contingent real debt ex-post via 

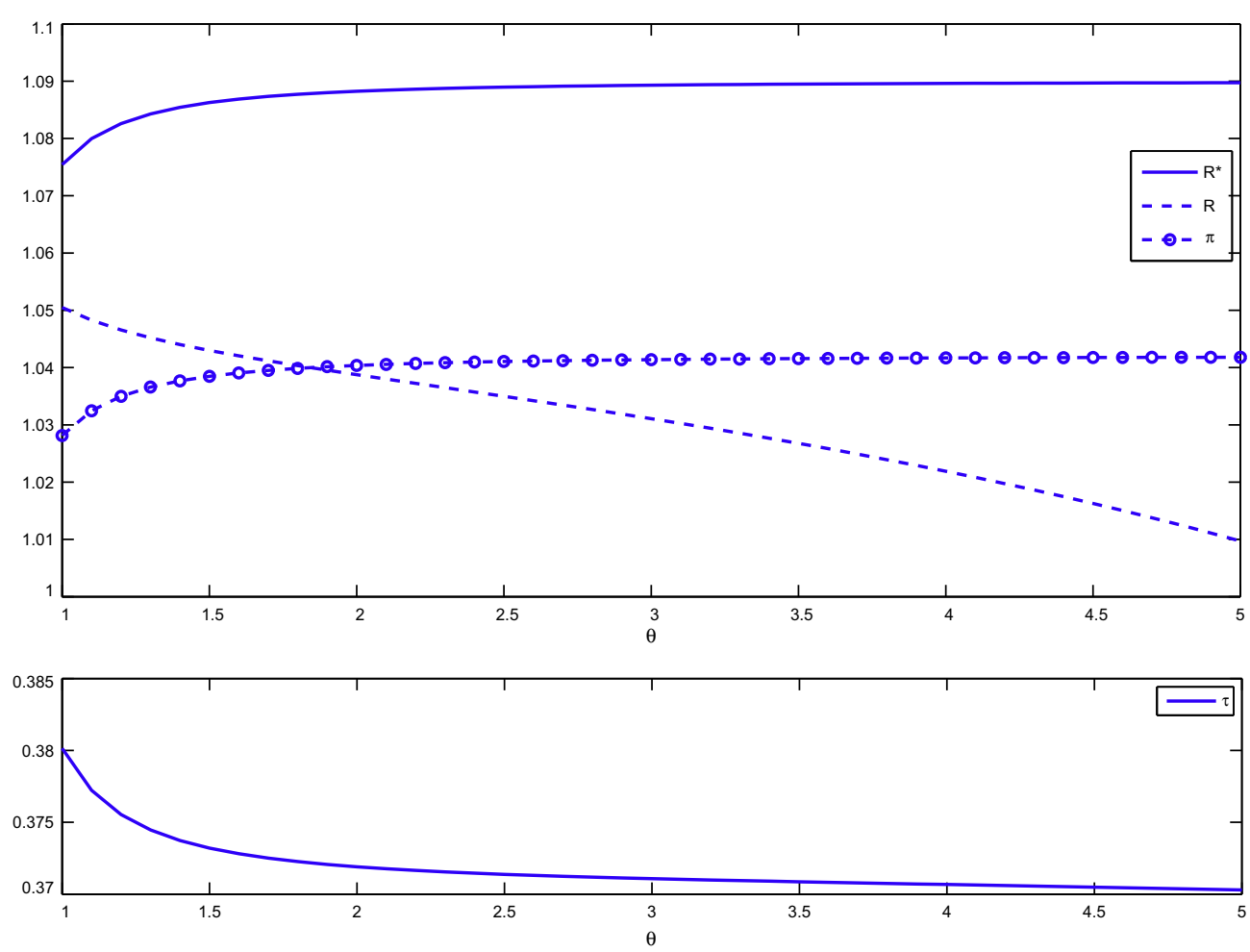

(a)Taxinstruments.

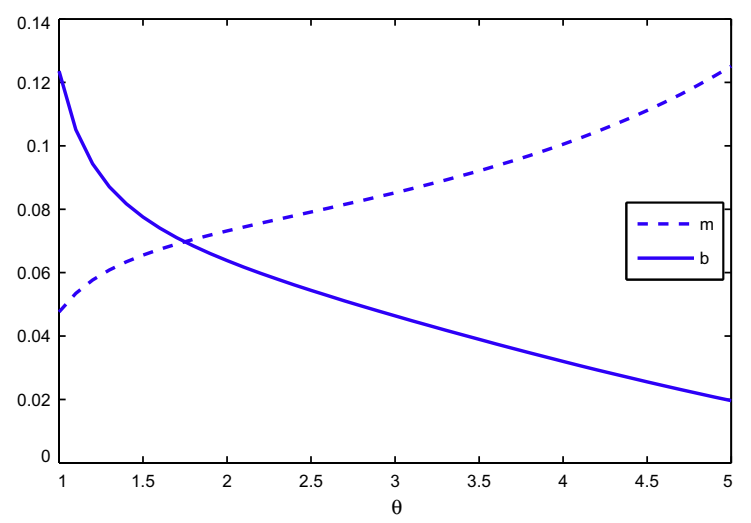

(b)Liquid bond and real money balance.

Fig. 1. Unconditional means under increasing price stickiness environments.

the tax on bond liquidity, as measure by $R^{*}$ relative to $R$. This channel becomes more important where there is a sticky-price constraint exerting cost on the planner to use inflation to make ex-post real debt state contingent. Thus one can observe in both $\mathrm{SP}^{*}$ and SP, there is even less volatility induced in inflation as the planner uses the interest-rate spread instead to satisfy the implementability constraints in the optimal policies.

What is different in this model is that labor income tax volatility can also be reduced when there is liquidity service of government bonds. The reason for this result can be found by inspecting the optimal trade-offs facing private agents and the planner. Suppose, the planner has picked some (optimal) process for inflation. Now consider Eq. (25), the optimal consumption-leisure trade-off for a competitive consumer.

On the one hand, a planner can use variations in labor income tax $\tau$ to satisfy the conditions for an optimal planning problem, which include sticky-price (23) and implementability constraints (24). However, too much variability in $\tau$ distorts labor supply and hence the production of output. On the other, the planner could also minimize the variability of $\tau$, thus minimizing the distortion on labor supply and production, and instead induce variations in government bond holdings via the implicit taxation of liquid government bonds $R^{*}-R$ in (26). 

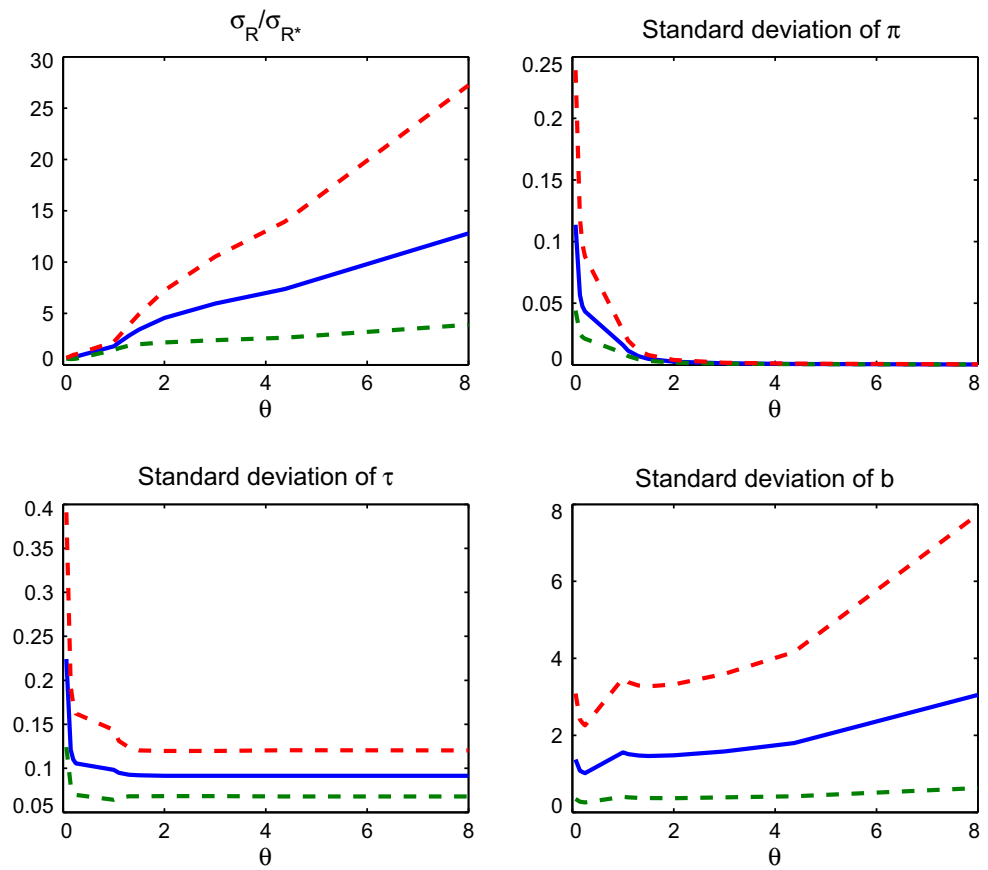

Fig. 2. Tax instrument volatilities in percentage standard deviation under increasing price stickiness environments.

Given an inflation and income tax plan $\left\{\Pi_{t}\left(z_{0}, g_{0}\right), \tau_{t}\left(z_{0}, g_{0}\right)\right\}_{t=0}^{\infty}$, the planner has the additional degree of freedom to pick a plan $\left\{R_{t}^{*}\left(z_{0}, g_{0}\right)-R_{t}\left(z_{0}, g_{0}\right)\right\}_{t=0}^{\infty}$ such that it satisfies implementability (24) and optimal firm pricing (23). Thus, there exists such a plan with minimal volatility in inflation and income tax, with a trade-off in the volatility of the spread $R^{*}-R$ (and thus $b$ ) which only distorts the consumer's composition of liquid assets (money and government bond) in the CIA constraint (7) and the consumer's intertemporal substitution of consumption via (10). The latter could easily be offset by picking the optimal inflation plan that also minimizes distortions to intertemporal consumption allocation (10). The intuition of this optimal intertemporal smoothing plan is supported by the autocorrelation coefficients across the four economies. Tax on labor generally stays highly persistent, whereas inflation becomes less persistent, but the interest spread becomes more persistent. $^{6}$

\subsection{Volatility properties under price stickiness}

In this second part of the numerical exercise, we consider in more detail how the existence of liquid government bonds alter the Ramsey plan in sticky-price environments, in terms of across-state and across-date allocations. These two features are summarized by volatility (in percentage standard deviations) and persistence (first-order autocorrelations) statistics of the key tax instrument variables. We fix the parameter that determines bond liquidity at the baseline value of $\phi=0.149$, and then consider a subset of increasingly sticky-price economies, as measured by $\theta$.

Fig. 2 plots the averages of the same statistics with their respective $90 \%$ confidence intervals, as a function of the degree of price stickiness, $\theta$. Each point on the graphs in the lower panel represents an averaged statistic, for an economy indexed by $\theta$, for Monte Carlo simulations of length $T=100$ repeated for $H=1000$ history paths. The sample histories are kept the same for each economy indexed by $\theta$.

In the face of shocks to government spending and technology, optimal policy is geared towards greater price stability. It can be seen that as $\theta$ rises from a near flexible-price economy $(\theta \approx 0)$ to a very sticky-price one $(\theta=8)$, the volatility of inflation, $\Pi$ decreases. However, we also see a rise in the volatility of $R$ relative to $R^{*}$ (and therefore in the volatility of liquid bond, $b$ ). It can also be seen that labor income tax, $\tau$, becomes less volatile as $\theta$ increases.

In order to achieve lower inflation volatility since inflation is more costly as price stickiness rises, the planner creates more volatility in the ex-post real return on government debt and the government debt itself. The greater volatility in the return on government debt and the debt itself means that the planner can use debt as a shock absorber whilst minimizing the shock absorbing role of inflation or labor income tax when financing government spending. This result affirms the intu-

\footnotetext{
${ }^{6}$ If one observes the role of government debt dynamics in affecting the planner's date and state-contingent implementability constraints, What really makes government bonds matter is the liquidity function $b \mapsto k(b)$ and the marginal liquidity function $b \mapsto k^{\prime}(b)$. Thus, the result could be extended to have private bonds $b^{*}$ providing such a function as well. We thus conjecture that similar results would obtain if we allow private assets to have some liquidity features.
} 


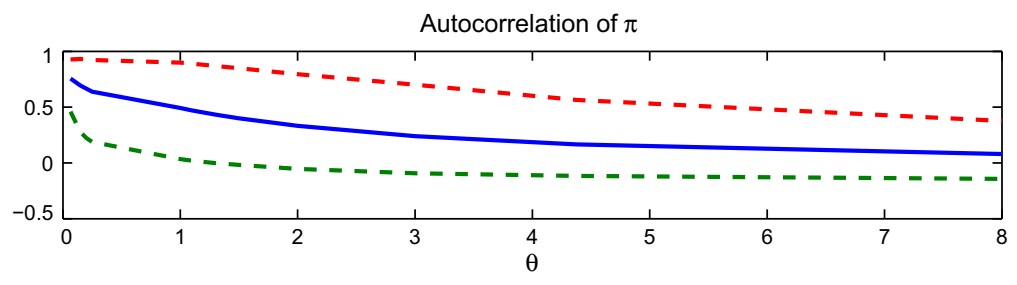

Autocorrelation of $\tau$

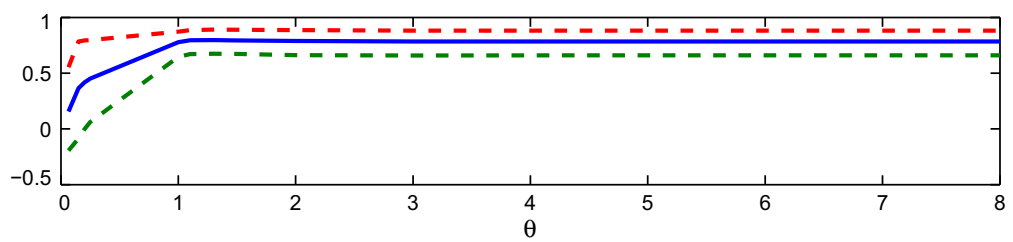

Autocorrelation of $b$

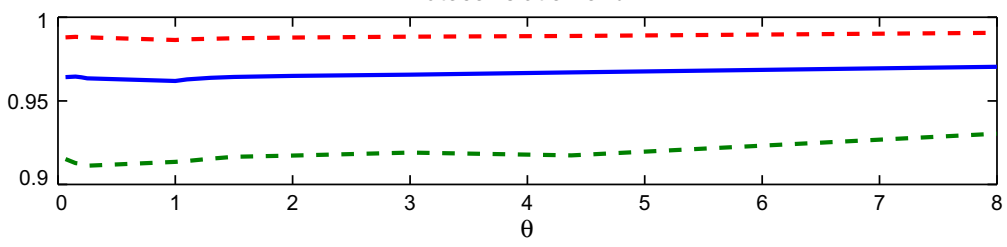

Fig. 3. Autocorrelations under increasing price stickiness environments.

ition discussed in Section 5.1.2 - labor income tax becomes less volatile as $\theta$ increases - in contrast with that of Siu (2004) and Schmitt-Grohé and Uribe (2004a) in the relevant parameter domain of $\theta$. Specifically, Siu (2004) showed that as price stickiness increases the volatility of labor income tax rate rises because the planner in that case forgoes minimizing labor tax volatility in favor of a lower inflation volatility. Our result is different because government bonds are held by households partly to provide liquidity. Thus, instead of distorting labor supply and hence output by increasing the volatility of labor tax rate, the planner in our model chooses to distort the distribution of liquidity between government bonds and money. Thus we see a greater volatility on $R$ and $b$, while a lower volatility on $\tau$ as $\theta$ rises.

Part of the optimal tax program involves intertemporal smoothing of taxes and therefore allocations. Fig. 3 plots the firstorder autocorrelations of the key fiscal and monetary variables as functions of the degree of price stickiness, $\theta$. We can see that as $\theta$ moves from a flexible-price economy to one which has a lot stickiness $(\theta=8)$, labor income tax rate, $\tau$, and liquid government debt, $b$, are increasingly more persistent to the extent of being near random walks. The converse is true for inflation, $\pi$. In order to minimize the costly effect of inflation when price stickiness increases, the optimal program makes inflation less and less autocorrelated so that, in combination with less volatile inflation, the cost of inflation is smaller.

Finally, Fig. 4 plots the Monte Carlo contemporaneous correlation of the tax instruments with output, with their respective $90 \%$ confidence intervals, as a function of the degree of price stickiness, $\theta$. A negative correlation between $R$ and $y$ suggests that in good times the planner would like to partially reduce its debt burden by lowering the return on government debt. This is equivalent to increasing the tax rate on bond liquidity. Similarly, in good times, when $y$ is high, the planner would like to tax labor, $\tau$, at a higher rate. Both these outcomes are consistent with a planner that aims to smooth out tax distortions over time and across states.

\subsection{Robustness and the effect of bond liquidity}

In this third exercise, we investigate the effect of the government bond liquidity on the optimal policy plan for feasible values of $\phi$. This exercise allows us to see how $\phi$ affects the optimal policy plan when both technology and government spending shocks are present, and also serves as a check on the sensitivity of our previous result in Section 5.2. We repeat the exercise of analyzing the optimal policy under different price stickiness environments, across different values of $\phi .{ }^{7}$ Here we will focus on the unconditional means and standard deviations of the tax instruments.

Fig. 5 plots the volatility of the key variables as functions of a set of economies indexed by $(\phi, \theta)$, where each economy (as a point on the surfaces) is made to share the same set of histories of stochastic technology and government spending shocks. Thus, we can consider the effect on the optimal volatility of our variables of interest as we vary the degree of price stickiness $\theta$, for different cases of $\phi$.

\footnotetext{
${ }^{7}$ While our baseline calibration of $\phi=0.149$ is consistent with a non-stochastic steady state spread of $\bar{R}^{*}-\bar{R}=0.05$ per annum, a number estimated by Bansal and Coleman (1996), one might also consider alternative spreads. In this exercise, we thus account for various spreads. For example, $\phi \approx 0.0598$ is consistent with a $1.1 \%$ spread per annum.
} 

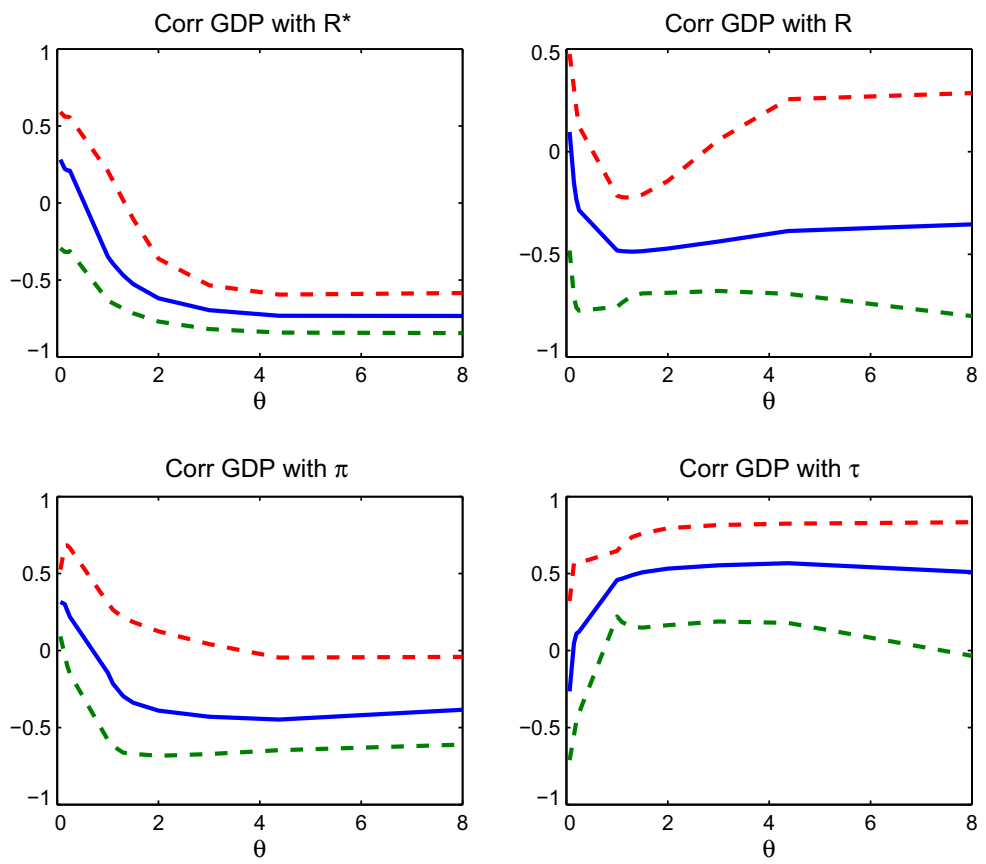

Fig. 4. Tax instrument contemporaneous correlation with GDP.
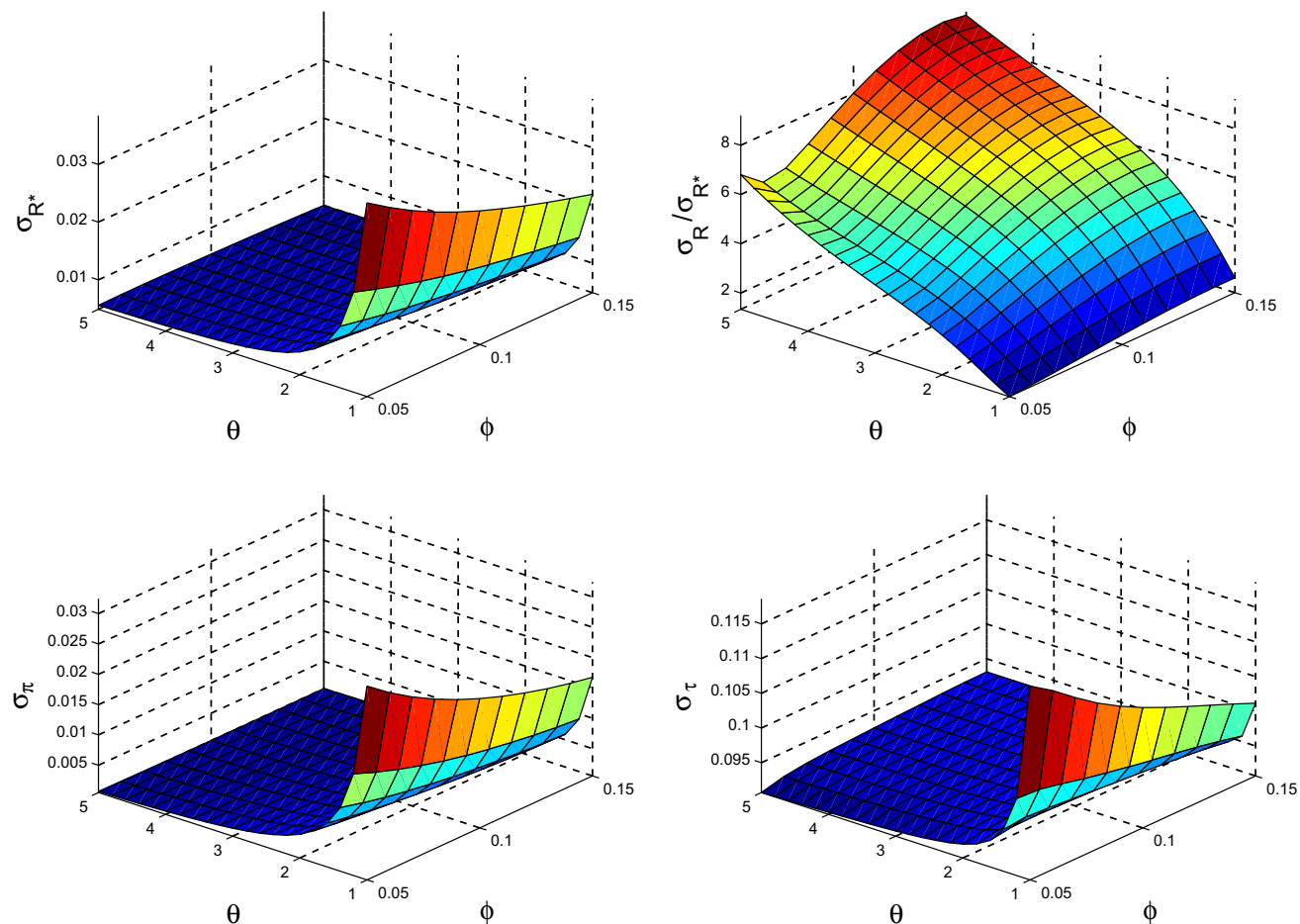

Fig. 5. Tax instrument volatilities as functions of economies indexed by $(\phi, \theta)$. Each point on the surfaces are generated by the same set of histories of exogenous shocks. Averages of statistics for Monte Carlo simulation $T=100, H=1000$.

We obtained the following results. First, with more price stickiness and given a particular degree of bond-money substitutability, $\phi$, there is a rise in the volatility of government bond return, $R$, relative to the market-bond return, $R^{*}$, but a fall in the volatility of inflation and labor tax. In other words, the government can use the bond liquidity tax (and hence government debt) as a shock absorber in order to lower two kinds of social costs - inflation cost which increases with price 

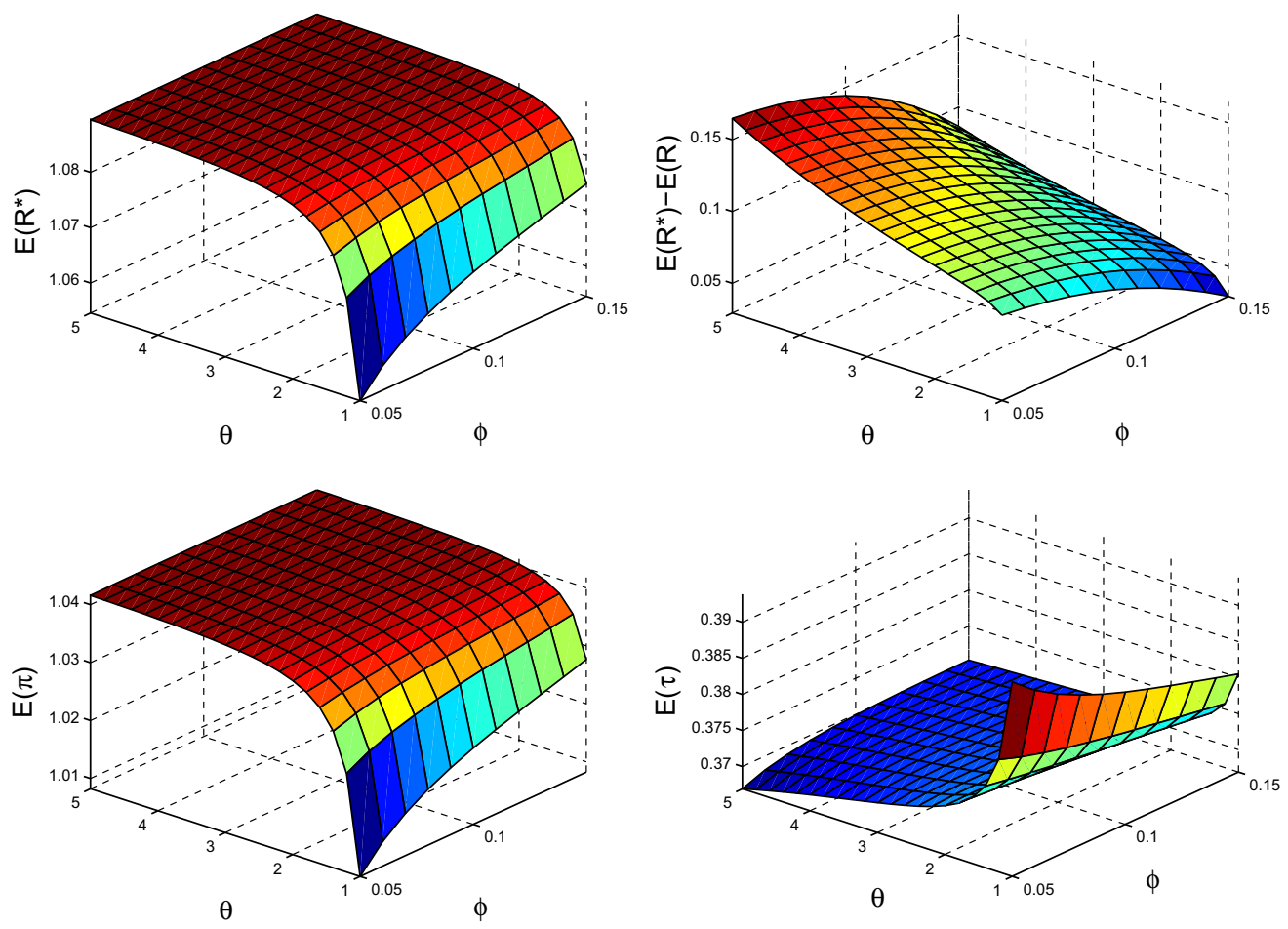

Fig. 6. Tax instrument unconditional means as functions of economies indexed by $(\phi, \theta)$. Each point on the surfaces are generated by the same set of histories of exogenous shocks. Averages of statistics for Monte Carlo simulation $T=100, H=1000$.

stickiness and labor distortion cost which increases with the volatility of income tax. This again affirms the result from Section 5.2 for various computationally feasible values of $\phi$.

Second, for each given price stickiness level, $\theta$, the greater is $\phi$ (i.e. moving from an implied steady state annual interest spread of just under $1 \%$ toward $5 \%$ ) the more the planner can afford to reduce the uncertainty of inflation and labor tax rates while increasing the volatility of the interest spread between market and bond returns. Intuitively, in an economy with greater liquidity effect of government bonds (higher $\phi$ ), the "cost" of using bond tax is lower relative to the cost of using inflation tax and labor tax. This is because for equal opportunity cost of holding liquid bonds $R^{*}-R$, a higher money-bond substitutability results in a larger demand for government bonds which means a larger tax base in terms of bond tax, since $k^{\prime}(b ; \phi)>k^{\prime}(b ; \tilde{\phi})$ for all $\tilde{\phi}>\phi$. This argument is shown graphically in Fig. 7. This effect is further enhanced by the planner allowing for a lower spread on average, $R^{*}-R$, as shown in Fig. 6, as $\phi$ increases. Thus, with relatively greater holdings of liquid government bonds as $\phi$ rises, the planner allows for more volatility on the bond rate - a surprise interest-rate tax, given inflation tax is too costly - for a given degree of price stickiness.

\subsection{Optimal policy rule, liquid bonds, and individual shocks}

In our fourth exercise, we infer what an optimal Ramsey policy plan looks like with respect to the primitive shocks that drive the fluctuations in this economy. ${ }^{8}$ First, we consider simple correlation of the policy instruments with respect to the model's primitive shocks. Second, we provide more detailed explanation of the correlation results using impulse response analysis. We keep the parameterization of the model as in the baseline case in Table 1 but vary $\phi$.

Productivity shock: As in standard equilibrium business cycle models the process $\left\{R^{*}\right\}$, is negatively correlated with productivity shocks, $\{z\}$, as shown in Table 3. A positive $z$ raises the marginal product of labor (14) and supply of output (3), and given expected inflation, $R^{*}$ must fall to induce more consumption in (10) in equilibrium. This is also shown in Fig. 8.

As output supply rises, this causes inflation to fall. However, in this model, deviations in inflation that are too large from steady state tends to be costly in real terms. This resource cost of inflation is given by the resource constraint in equilibrium in (18).

Consistent with the experimental results earlier in Section 5.3, the planner with the extra liquid-bond tax instrument chooses to stabilize inflation and labor income tax, by manipulating the path of $R$ relative to $R^{*}$. Thus the planner optimally

${ }^{8}$ We thank an anonymous referee for suggesting this exercise. 


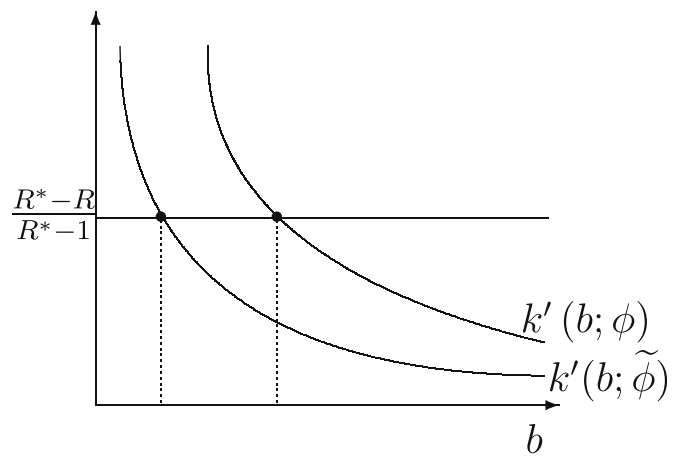

Fig. 7. Example with $\phi>\tilde{\phi}$. For equal opportunity cost of holding government bonds, a higher $\phi$, results in higher bond holdings.

Table 3

Correlation of policy variables $\left\{R^{*}, R, \tau\right\}$ with primitive state variables $(z, g)$.

\begin{tabular}{lll}
\hline Variable, $x$ & $\operatorname{corr}(x, z)$ & $\operatorname{corr}(x, g)$ \\
\hline Nominal return on private assets, $R^{*}$ & -0.75 & 0.11 \\
Nominal return on government bonds, $R$ & 0.16 & 0.15 \\
Spread $R^{*}-R$ & -0.26 & -0.15 \\
Labor income tax rate, $\tau$ & 0.94 & 0.32 \\
\hline
\end{tabular}

Statistics are from the baseline model with sample size $T=100$, repeated for $H=1000$ times.
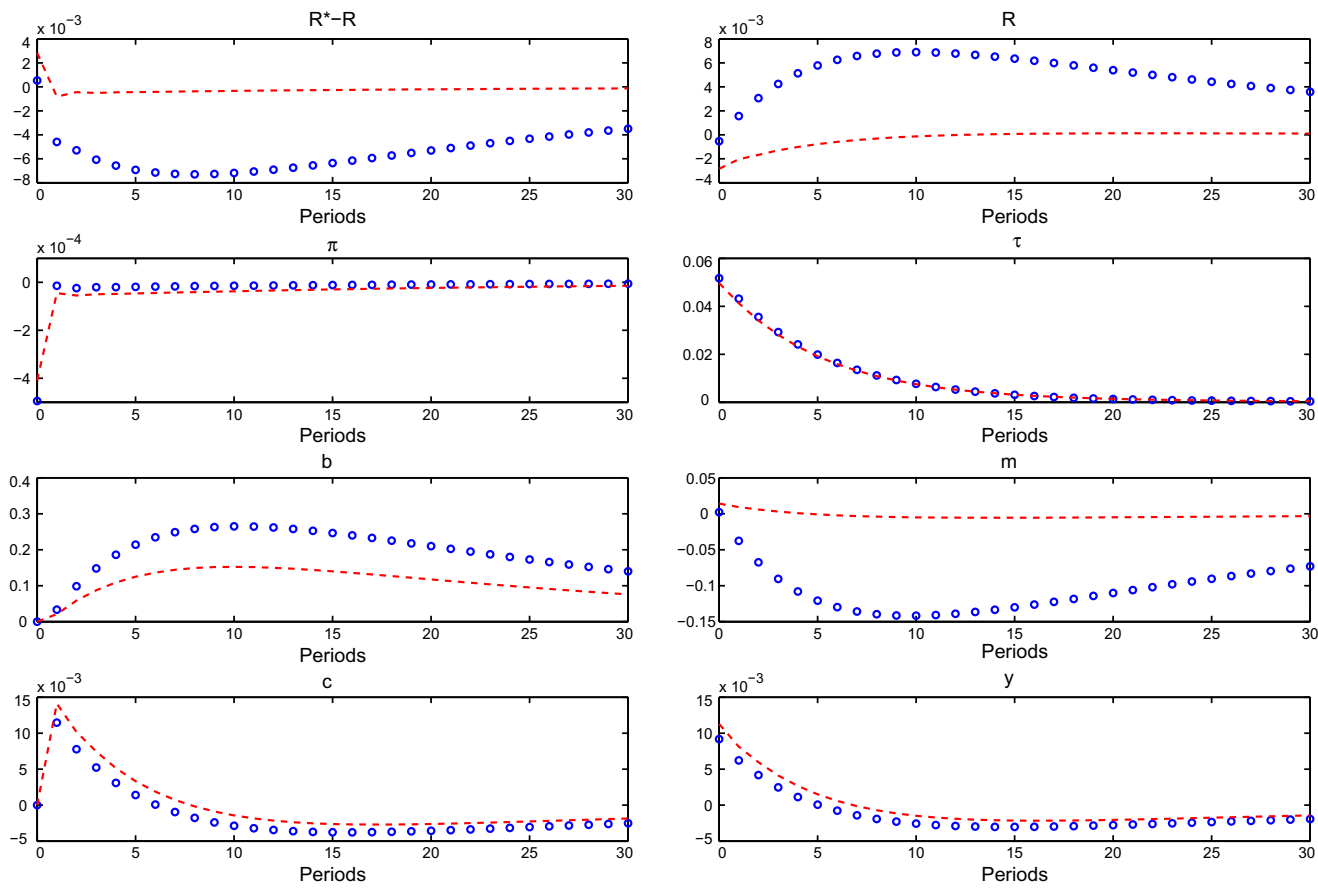

Fig. 8. Impulse response functions to one standard deviation $\left(\sigma_{z}=0.023\right)$ i.i.d. technology shock in two economies with different government bond liquidity, $\phi$. Circles $(\phi=0.15)$ and Dashed $(\phi \searrow 0)$.

induces a bond liquidity spread process, $\left\{R^{*}-R\right\}$ that turns out to be negatively correlated with $\{z\}$. This is depicted in Fig. 8 . We explain this as follows.

First, note that the immediate inflation response to $z$ is marginally higher when $\phi$ is higher. However, for the remaining periods the deviation of inflation from steady state is always less in the economy with higher $\phi .{ }^{9}$ This is because the optimal

\footnotetext{
${ }^{9}$ In our previous analyses, we had both shocks active, and thus, inflation volatility induced by the optimal policy does decline with $\phi$.
} 

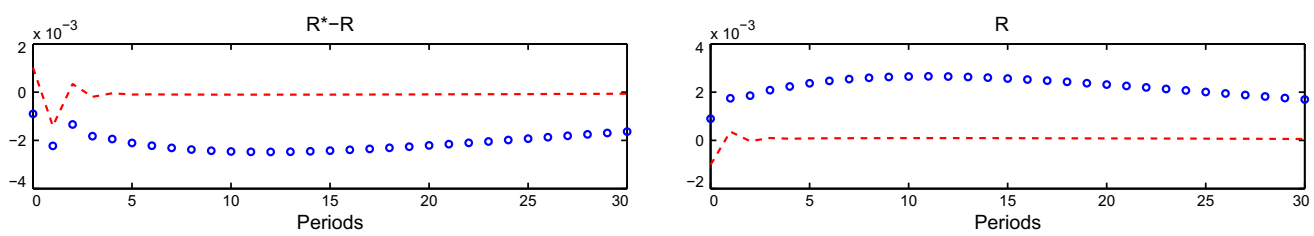

$\pi$
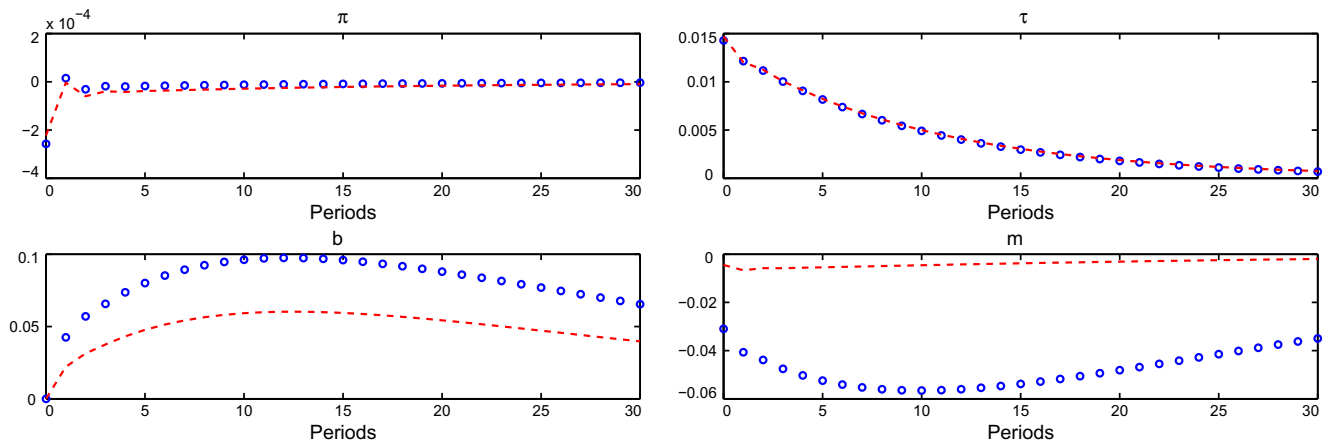

$\mathrm{m}$

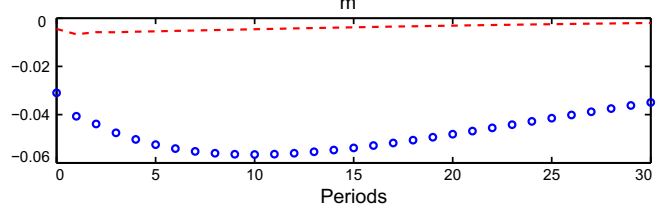

c
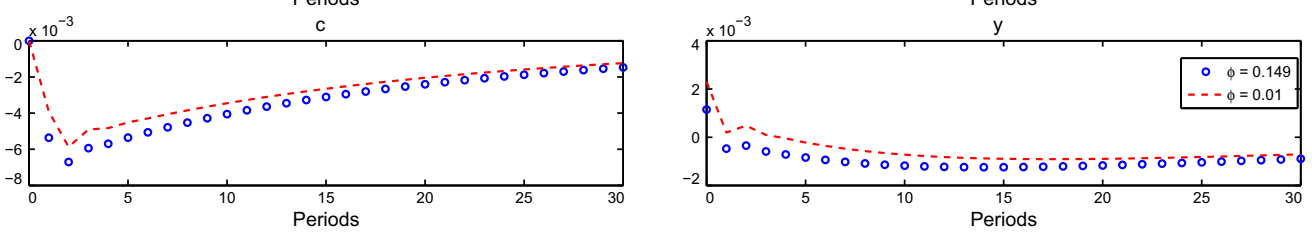

Fig. 9. Impulse response functions to one standard deviation $\left(\sigma_{g}=0.03\right)$ i.i.d. government spending shock in two economies with different government bond liquidity, $\phi$. Circles $(\phi=0.15)$ and Dashed $(\phi \searrow 0)$.

Ramsey policy, given a productivity increase, tolerates only very small declines in inflation over the medium to long term to maintain stable inflation expectations, while allowing consumption and output to increase in the short term. Second, the effects of a higher path $\{z\}$ has a tendency to increase the expected present value of the utility value of government surpluses (i.e., LHS of (24)), all else constant. To satisfy implementability constraints and sticky-price constraints, the planner, in the economy with government bonds that have greater transactions services (higher $\phi$ ), can thus allow large declines in the spread $R^{*}-R$ to induce more holdings of liquid government bonds, $b$, while preventing too much variation in inflation and labor income tax rates.

Hence, the observation in the baseline model that the bond liquidity spread and productivity shock processes are negatively correlated, along with the outcome that a productivity increase can be accommodated as increases in output and consumption with an overall small decline in inflation and very little change in the response of labor income tax rates.

Government spending shock: A positive $g$ tends to increase the demand for output and crowd out consumption, and given expected inflation, raise the market return on private bonds $R^{*}$. Hence, the positive correlation of $\left\{R^{*}\right\}$ with $\{g\}$ in Table 3 . This is also shown in Fig. 9. With higher bond liquidity effect, $\phi$, the path of labor tax is positive but kept lower than the case with near zero bond liquidity. The response of inflation is slightly positive in the second period, but is kept remarkably close to steady state, especially when $\phi$ is high. Thus by inducing a response of large declines in the spread $R^{*}-R$, so that it is negatively correlated with $g$, the planner can still afford to finance a higher path of $\{g\}$ with bonds, rather than inflation front-loading or labor income tax as means of satisfying its policy implementability constraints.

In summary, the optimal plan in the face of either shock, allows the interest spread to adjust by larger amplitudes and thus using government bond holdings more as the shock absorber, when implementability constraints have to be met, and when inflation is costly. This then shows up as a greater response in the process for government bonds. As these impulse responses suggest, for a given baseline degree of price stickiness in the economy, the optimal bond liquidity tax wedge, $R^{*}-R$, is more quantitatively important the more liquid is government bonds. And as explained in Sections 5.2 and 5.3 , this additional degree of freedom allows the planner to minimize the use of labor income taxes and inflation as means of public finance. Thus, from an optimal policy and quantitative perspective, the channel via $\phi$ may be quite important in contributing to lowering the impact on inflation and distortionary labor taxes. This aids a policy maker's commitment to achieving long term inflation and income tax stabilization. In the following section, we quantify this claim by mapping the outcomes into a single quantitative measure of welfare.

\subsection{Quantitative welfare effects}

In this fifth exercise, we consider quantitatively how important is $\phi$ in contributing to ex-ante welfare of the private agents in the economy. We consider the benchmark case only, with the two different values of $\phi$ from the previous section. We consider the benchmark sticky-price economy (A) with $\phi_{A}=0.149$ and the limiting economy (B) with $\phi_{B} \backslash 0$. 


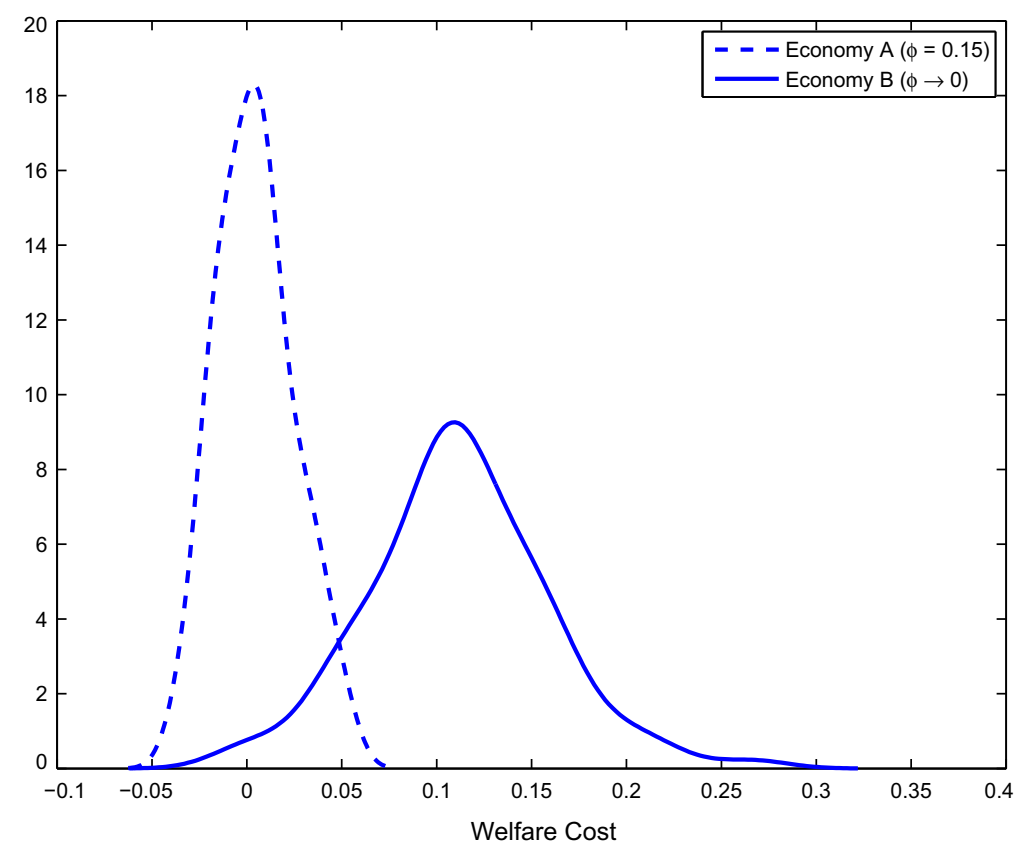

Fig. 10. Sample densities of welfare cost statistics for $\Omega_{i}, i \in\{A, B\}$ generated under the same set of histories of exogenous shocks, of length $T=10000$ and $H=1000$ paths.

Following Lucas (1987), we can calculate the quantitative welfare effects of this new tax channel, whose strength is indexed by $\phi$. For each economy $i \in\{A, B\}$, let its particular Ramsey equilibrium be denoted as $\sigma_{i}\left(z_{0}, g_{0}\right)$. Define $\Omega_{i}$ as the proportional shift, from steady state, to each random consumption path (i.e., compensating variation in consumption units) that would yield the same welfare in the stochastic economy $i \in\{A, B\}$ induced by $\sigma_{i}\left(z_{0}, g_{0}\right)$ as the welfare in the non-stochastic steady state of economy $i \in\{A, B\}$. Now denote $\bar{c}_{i}$ and $\bar{h}_{i}$ as the non-stochastic steady state consumption and hours worked for a particular economy $i$. Thus, $\Omega_{i}$ satisfies the equation

$$
\begin{aligned}
(1-\beta) \mathbb{E}_{\sigma_{i}\left(z_{0}, g_{0}\right)} & \left\{\sum_{t=0}^{\infty} \beta^{t} U\left[\left(1+\Omega_{i}\right) c_{t}, h_{t}\right]\right\}=(1-\beta) \sum_{t=0}^{\infty} \beta^{t} U\left[\mathbb{E}_{\sigma_{i}\left(z_{0}, g_{0}\right)}\left(c_{t}\right), \mathbb{E}_{\sigma_{i}\left(z_{0}, g_{0}\right)}\left(h_{t}\right)\right] \\
& =(1-\beta) \sum_{t=0}^{\infty} \beta^{t} U\left(\bar{c}_{i}, \bar{h}_{i}\right),
\end{aligned}
$$

where $\mathbb{E}_{\sigma_{i}\left(z_{0}, g_{0}\right)}$ is short-hand notation for the expectations operator applied to the random total discounted utility flows, whose probability measure is induced by a particular Ramsey equilibrium denoted as $\sigma_{i}\left(z_{0}, g_{0}\right)$, for $i \in\{A, B\}$.

Since we assumed per-period utility of the form $U\left(c_{t}, h_{t}\right)=\ln c_{t}+\delta \ln \left(1-h_{t}\right)$, and letting $\hat{c}_{t}:=\ln \left(c_{t}\left[\sigma_{i}\left(z_{0}, g_{0}\right)\right] / \bar{c}_{i}\right)$ and $\hat{h}_{t}:=\ln \left(h_{t}\left[\sigma_{i}\left(z_{0}, g_{0}\right)\right] / \bar{h}_{i}\right)$, then we can calculate ${ }^{10}$

$$
\ln \left(1+\Omega_{i}\right) \approx-(1-\beta) \mathbb{E}_{\sigma_{i}\left(z_{0}, g_{0}\right)}\left\{\sum_{t=0}^{\infty} \beta^{t}\left[\hat{c}_{t}-\left(\frac{\delta \bar{h}_{i}}{1-\bar{h}_{i}}\right) \hat{h}_{t}\right]\right\}, \quad i \in\{A, B\} .
$$

Thus, the welfare cost of fluctuations for each economy $i \in\{A, B\}$ is given by $\ln \left(1+\Omega_{i}\right)$, or $\Omega_{i}$ is per-period compensation in percentage deviation from steady state consumption terms.

We numerically calculate $\Omega_{i}, i \in\{A, B\}$. Since each estimate of $\Omega_{i}$ may be dependent on initial conditions, we calculate it for $H=1000$ sample paths, each of length $T=10,000$, and look at the resulting sample distribution of these estimates. A plot of the densities of welfare costs in both economies is given in Fig. 10. The distribution of compensating variation in consumption (i.e., welfare cost), as a percentage deviation from steady state, in the Ramsey equilibrium with greater bonds transactions service (Economy A) is clearly dominated by that of the Ramsey equilibrium with no bonds transactions service (Economy B).

The statistics of these distributions of welfare costs are given in Table 4. Again, we can see that on average, the gain to the economy with the bond liquidity channel permits the Ramsey planner to induce a competitive equilibrium that has lower

\footnotetext{
$\overline{10}$ Derivations are provided in Appendix D.
} 
Table 4

Welfare cost statistics for $\Omega_{i}, i \in\{A, B\}$.

\begin{tabular}{lll}
\hline & Mean & Standard deviation \\
\hline Economy A $(\phi=0.15)$ & 0.0047 & 0.0204 \\
Economy B $(\phi \searrow 0)$ & 0.1190 & 0.0526 \\
\hline
\end{tabular}

Averages of statistics for Monte Carlo simulation generated under the same set of histories of exogenous shocks, of length $T=10000$ and $H=1000$ paths

welfare cost of fluctuations from steady state. Quantitatively, the difference in welfare costs, due to the channel $\phi$ is quite sizable. On average, the welfare cost of fluctuations in the economy without the liquid-bond channel (Economy B) is about 24 times larger than that in the benchmark economy with liquid bonds (Economy A).

However, this gain in welfare in Economy A should not be surprising. If the planner has access to an extra tax instrument, in the form of the liquid-bond tax wedge that helps to relax its implementability and sticky-price constraints, then the resulting welfare improvement should be sizable. Nevertheless, we make no definitive claims as to the size of these gains. The welfare cost calculations, conditional on the rest of the model, would depend on the specification of the household preference function $U$, the bond liquidity function $k$ and/or the calibration of $\phi$. How realistic these specifications are is a question for more accurate econometric validation and would be beyond the scope of this paper.

\section{Conclusion}

We constructed a model where government bonds provide liquidity service, an idea that goes back to the work of Tobin (1965) and Patinkin (1965) and supported by the observation that US Treasury bills have a role in facilitating transactions.

We showed in the paper that when a government bond plays a dual role of providing liquidity as well as a traditional function as a financial asset, it alters the Ramsey optimal fiscal and monetary policy equilibrium allocations. We found that in environments of increasing price stickiness inflation becomes less volatile and less persistent and labor income tax is less volatile. However, both the quantity of government debt and its return to the debt holder become more volatile and more persistent. Further, the labor income tax rate remains very persistent, reflecting a tax smoothing outcome. Also, the interestrate spread is increasing with the degree of price stickiness, reflecting the increasing tax on bond liquidity.

Thus, with increasing price stickiness the Ramsey optimal monetary policy is to stabilize inflation, foregoing the shock absorbing role of inflation in creating an ex-post state-contingent government debt. The corresponding optimal fiscal policy is to minimize labor income tax distortions, over time (tax smoothing) and across states (lower volatility). In return for the gain in low inflation volatility and low intertemporal income tax distortions, the optimal policy uses liquid government bonds as a means of shock absorption. We show that this result is robust across feasible parameterizations of bond liquidity and also in the face of government spending shocks and technology shocks. Quantitatively, we show that the additional tax instrument created by the bond liquidity channel can yield a sizable welfare gain from an economy without this channel.

\section{Acknowledgement}

We thank Kirdan Lees, Aditya Goenka, Junsang Lee, Farshid Vahid, Guillaume Rocheteau, Adrian Pagan, Heather Anderson, Thomas Lubik, Ana Maria Santacreu, Iris Claus, David Cook and Danyang Xie for beneficial conversations or comments, and seminar participants at the Australian National University, Hong Kong University of Science and Technology, the Macroeconomics Workshop in Melbourne, the 2005 EEA Congress in Amsterdam, the Reserve Bank of New Zealand DSGE Workshop, and the 2006 Public Economic Theory Conference in Hanoi.

\section{Appendix A. Proof of Proposition 1}

First show that the plan $\left\{c_{t}, h_{t}, \Pi_{t}, m c_{t}, b_{t}, R_{t}^{*}\right\}_{t=0}^{\infty}$ satisfying Definition 1 also satisfies (18), (22a), (22b), (23), (24). Use (7) to eliminate $m_{t}$, (26) to eliminate $R_{t}$, and (13) and (14) to eliminate $\tau_{t}$, from the real government budget constraint (20). This yields (22a) and (22b) for $t \geqslant 0$. Using (11), (10) and (12) we can construct $\lambda_{t}=U_{c}\left(c_{t}, h_{t}\right) /\left(2-R_{t}^{*-1}\right)$ for all $t$ and all states, and use this to eliminate $\lambda_{t}$ and $\lambda_{t+1}$ from (17) to yield (23). To show that the decentralized equilibrium satisfies the time- $t$ implementability constraint, for $t, s \geqslant 0$, (19) can be written as

$$
M_{t+s}+B_{t+s}+P_{t+s} \tau_{t+s} m c_{t+s} z_{t+s} h_{t+s}=R_{t+s-1} B_{t+s-1}+M_{t+s-1}+P_{t+s} g_{t+s}
$$

Let $D_{t+s}:=\prod_{i=0}^{s} R_{t+i-1}^{-1}$ and $W_{t+s}:=R_{t+s-1} B_{t+s-1}+M_{t+s-1}$

Thus, we can write $B_{t+s}=\left(W_{t+s+1}-M_{t+s}\right) R_{t+s}^{-1}$. Substituting these definitions into (29), and multiplying (29) with $D_{t+s}$ we obtain

$$
D_{t+s} M_{t+s}\left(1-R_{t+s}^{-1}\right)+D_{t+s} R_{t+s}^{-1} W_{t+s+1}-D_{t+s} W_{t+s}=D_{t+s}\left(P_{t+s} g_{t+s}-P_{t+s} \tau_{t+s} m c_{t+s} z_{t+s} h_{t+s}\right) .
$$

Summing this from $s=0$ to $S>0$, and taking expectations conditional on information at time $t$ : 
$\mathbb{E}_{t} \sum_{t=0}^{S}\left[D_{t+s} M_{t+s}\left(1-R_{t+s}^{-1}\right)-D_{t+s}\left(P_{t+s} g_{t+s}-P_{t+s} \tau_{t+s} m c_{t+s} z_{t+s} h_{t+s}\right)\right]=\mathbb{E}_{t} D_{t+S+1} W_{t+S+1}+D_{t} W_{t}$.

Let $S \rightarrow \infty$ and invoking (21), we have $\lim _{S \rightarrow \infty} \mathbb{E}_{t} D_{t+S+1} W_{t+S+1}=0$ and thus,

$\mathbb{E}_{t} \sum_{t=0}^{\infty}\left(\prod_{i=1}^{s} R_{t+i-1}^{-1}\right)\left[M_{t+s}\left(1-R_{t+s}^{-1}\right)-\left(P_{t+s} g_{t+s}-P_{t+s} \tau_{t+s} m c_{t+s} z_{t+s} h_{t+s}\right)\right]=W_{t}$.

Making use of (10) to find $R_{t}^{*} R_{t+1}^{*} \cdots R_{t+s-1}^{*}$, we can derive

$$
\mathbb{E}_{t}\left[\beta^{s}\left(\frac{\lambda_{t+s} P_{t}}{\lambda_{t} P_{t+s}}\right) \prod_{i=1}^{s} R_{t+i-1}^{*}\right]=1
$$

Multiply both sides of (30) with this to obtain

$$
\mathbb{E}_{t} \sum_{t=0}^{\infty}\left(\prod_{i=1}^{s} R_{t+i-1}^{-1} R_{t+i-1}^{*}\right) \frac{\beta^{s} \lambda_{t+s}}{P_{t+s}}\left[M_{t+s}\left(1-R_{t+s}^{-1}\right)-\left(P_{t+s} g_{t+s}-P_{t+s} \tau_{t+s} m c_{t+s} z_{t+s} h_{t+s}\right)\right]=\frac{\lambda_{t} W_{t}}{P_{t}} .
$$

and using (26), (7), (13) and (14) and $\lambda_{t}=U_{c}\left(c_{t}, h_{t}\right) /\left(2-R_{t}^{*-1}\right)$, to eliminate $R_{t+s}, \lambda_{t}, \lambda_{t+s}, M_{t+s} / P_{t+s}$, and using (18) to eliminate $g_{t+s}$ we can obtain (24).

Going backwards. Now show that $\left\{c_{t}, h_{t}, \Pi_{t}, m c_{t}, b_{t}, R_{t}^{*}\right\}_{t=0}^{\infty}$ satisfying (18), (22a), (22b), (23), (24) can implement the decentralized equilibrium in Definition 1 . Suppose that the economy is determined by the Ramsey plan satisfying (18), (22a), (22b), (23), (24). The planner can construct $\lambda_{t}$ that satisfies 10,11,12,13, 14 and (7). From these and (22a) we can recover $\left\{\tau_{t}, m_{t}, g_{t}\right\}$ that satisfy (19). Given $\lambda_{t}$ and $\lambda_{t+1}$ we can recover (17) from (23). Further $\left\{R_{t}\right\}$ can be recovered from (26) for given $\left\{b_{t}, R_{t}^{*}\right\}$. It remains to show that the decentralized equilibrium's transversality condition will not be violated. Since (19) can be recovered, re-write this at $t+s$ in time- $t$ value as

$$
\mathbb{E}_{t} \sum_{t=0}^{S}\left[\frac{D_{t+s} M_{t+s}}{P_{t} D_{t}}\left(1-R_{t+s}^{-1}\right)-\frac{D_{t+s}}{P_{t} D_{t}}\left(P_{t+s} g_{t+s}-P_{t+s} \tau_{t+s} m c_{t+s} z_{t+s} h_{t+s}\right)\right]=\mathbb{E}_{t} \frac{D_{t+S+1}}{P_{t} D_{t}} W_{t+S+1}+\frac{W_{t}}{P_{t}} .
$$

Since the time- $t$ implementability constraint is satisfied in the Ramsey plan, the limit of the LHS of (31) necessarily exists when $S \rightarrow \infty$, and this limit is $W_{t} / P_{t}$ such that the present value of the government budget surpluses equals exactly the initial condition on government liabilities. This implies $\lim _{S \rightarrow \infty} \mathbb{E}_{t} D_{t+S+1} W_{t+S+1}=0$. And rewriting for the definition of $D_{t+S+1}$ and $W_{t+S+1}$, we have

$$
\lim _{s \rightarrow \infty} \mathbb{E}_{t}\left(\prod_{i=0}^{s} R_{t+i}^{-1}\right)\left(R_{t+s} B_{t+s}+M_{t+s}\right)=0
$$

which is (21).

\section{Appendix B. The ramsey dual problem for numerical computations}

The Lagrangian for the Ramsey problem is

$$
\begin{aligned}
\mathscr{L} & =\mathbb{E}_{0} \sum_{t=0}^{\infty} \beta^{t}\left\{U\left(c_{t}, h_{t}\right)+\lambda_{t}^{c}\left[U_{c}\left(c_{t}, h_{t}\right)-\lambda_{t}\left(2-\frac{1}{R_{t}^{*}}\right)\right]+\lambda_{t}^{b}\left[\lambda_{t}-\beta R_{t}^{*} \mathbb{E}_{t} \frac{\lambda_{t+1}}{\Pi_{t+1}}\right]\right. \\
& +\lambda_{t}^{s}\left[c_{t}-k\left(b_{t}\right)+b_{t}+\left(m c_{t} z_{t}+\frac{U_{h}\left(c_{t}, h_{t}\right)}{\lambda_{t}}\right) h_{t}-\frac{c_{t-1}-k^{\prime}\left(b_{t-1}\right)}{\Pi_{t}}-\frac{\left(R_{t-1}^{*}-\left(R_{t-1}^{*}-1\right) k\left(b_{t-1}\right)\right) b_{t-1}}{\Pi_{t}}-g_{t}\right] \\
& +\lambda_{t}^{r}\left[z_{t} h_{t}-c_{t}-g_{t}-\frac{\theta}{2}\left(\Pi_{t}-\bar{\Pi}\right)^{2}\right]+\lambda_{t}^{p}\left[\beta \mathbb{E}_{t}\left(\frac{\lambda_{t+1}}{\lambda_{t}}\left(\Pi_{t+1}-\bar{\Pi}\right) \Pi_{t+1}\right)\right. \\
& \left.\left.+\frac{\eta}{\theta} z_{t} h_{t}\left(\frac{1+\eta}{\eta}-m c_{t}\right)-\left(\Pi_{t}-\bar{\Pi}\right) \Pi_{t}\right]\right\}
\end{aligned}
$$

with the first-order conditions for $t \geqslant 1$,

$$
\begin{aligned}
& U_{c}\left(c_{t}, h_{t}\right)+\lambda_{t}^{c} U_{c c}\left(c_{t}, h_{t}\right)+\lambda_{t}^{s}-\beta \mathbb{E}_{t} \frac{\lambda_{t+1}^{s}}{\Pi_{t+1}}-\lambda_{t}^{r}=0 \\
& U_{h}\left(c_{t}, h_{t}\right)+\lambda_{t}^{s}\left(m c_{t} z_{t}+\frac{U_{h h}\left(c_{t}, h_{t}\right) h_{t}+U_{h}\left(c_{t}, h_{t}\right)}{\lambda_{t}}\right)+\lambda_{t}^{r} z_{t}+\lambda_{t}^{p} \frac{\eta}{\theta} z_{t}\left(\frac{1+\eta}{\eta}-m c_{t}\right)=0 \\
& -\lambda_{t}^{c}\left(2-\frac{1}{R_{t}^{*}}\right)+\lambda_{t}^{b}-\lambda_{t-1}^{b} \frac{R_{t-1}^{*}}{\Pi_{t}}-\frac{\lambda_{t}^{s}}{\lambda_{t}^{2}} U_{h}\left(c_{t}, h_{t}\right) h_{t}-\lambda_{t}^{p} \beta \mathbb{E}_{t}\left(\frac{\lambda_{t+1}}{\lambda_{t}^{2}}\left(\Pi_{t+1}-\bar{\Pi}\right) \Pi_{t+1}\right)+\frac{\lambda_{t-1}^{p}}{\lambda_{t-1}}\left(\Pi_{t}-\bar{\Pi}\right) \Pi_{t}=0
\end{aligned}
$$




$$
\begin{aligned}
& -\frac{\lambda_{t}^{c} \lambda_{t}}{\left(R_{t}^{*}\right)^{2}}-\lambda_{t}^{b} \beta \mathbb{E}_{t} \frac{\lambda_{t+1}}{\Pi_{t+1}}+\beta \mathbb{E}_{t} \frac{\lambda_{t+1}^{s}}{\Pi_{t+1}}\left(1-k^{\prime}\left(b_{t}\right)\right) b_{t}=0 \\
& \lambda_{t}^{s}\left[1-k^{\prime}\left(b_{t}\right)\right]-\beta \mathbb{E}_{t} \frac{\lambda_{t+1}^{s}}{\Pi_{t+1}}\left\{\left[R_{t}^{*}-\left(R_{t}^{*}-1\right)\left(k^{\prime}\left(b_{t}\right)+b_{t} k^{\prime \prime}\left(b_{t}\right)\right)\right]+k^{\prime}\left(b_{t}\right)\right\}=0 \\
& \lambda_{t-1}^{b} R_{t-1}^{*} \frac{\lambda_{t}}{\Pi_{t}^{2}}+\frac{\lambda_{t}^{s}}{\Pi_{t}^{2}}\left[R_{t-1}^{*}-\left(R_{t-1}^{*}-1\right) k^{\prime}\left(b_{t-1}\right)\right] b_{t-1}+\frac{\lambda_{t}^{s}}{\Pi_{t}^{2}}\left[c_{t-1}-k\left(b_{t-1}\right)\right]-\theta \lambda_{t}^{r}\left(\Pi_{t}-\bar{\Pi}\right)+\left(\frac{\lambda_{t-1}^{p} \lambda_{t}}{\lambda_{t-1}}-\lambda_{t}^{p}\right)\left(2 \Pi_{t}-\bar{\Pi}\right)=0 \\
& \lambda_{t}^{s}=\frac{\eta}{\theta} \lambda_{t}^{p} \\
& U_{c}\left(c_{t}, h_{t}\right)=\lambda_{t}\left(2-\frac{1}{R_{t}^{*}}\right) \\
& \lambda_{t}=\beta R_{t}^{*} \mathbb{E}_{t} \frac{\lambda_{t+1}}{\Pi_{t+1}} \\
& c_{t}-k\left(b_{t}\right)+b_{t}+\left(m c_{t} z_{t}+\frac{U_{h}\left(c_{t}, h_{t}\right)}{\lambda_{t}}\right) h_{t}=\frac{c_{t-1}-k\left(b_{t-1}\right)}{\Pi_{t}}+\frac{\left(R_{t-1}^{*}-\left(R_{t-1}^{*}-1\right) k^{\prime}\left(b_{t-1}\right)\right) b_{t-1}}{\Pi_{t}}+g_{t} \\
& z_{t} h_{t}=c_{t}+g_{t}+\frac{\theta}{2}\left(\Pi_{t}-\bar{\Pi}\right)^{2} \\
& \left(\Pi_{t}-\bar{\Pi}\right) \Pi_{t}=\beta \mathbb{E}_{t}\left(\frac{\lambda_{t+1}}{\lambda_{t}}\left(\Pi_{t+1}-\bar{\Pi}\right) \Pi_{t+1}\right)+\frac{\eta}{\theta} z_{t} h_{t}\left(\frac{1+\eta}{\eta}-m c_{t}\right) .
\end{aligned}
$$

and the first-order conditions for $t=0$,

$$
\begin{aligned}
& U_{c}\left(c_{0}, h_{0}\right)+\lambda_{0}^{c} U_{c c}\left(c_{0}, h_{0}\right)+\lambda_{0}^{s}-\beta \mathbb{E}_{0} \frac{\lambda_{1}^{s}}{\Pi_{1}}-\lambda_{0}^{r}=0 \\
& U_{h}\left(c_{0}, h_{0}\right)+\lambda_{0}^{s}\left(m c_{0} z_{0}+\frac{U_{h h}\left(c_{0}, h_{0}\right) h_{0}+U_{h}\left(c_{0}, h_{0}\right)}{\lambda_{0}}\right)+\lambda_{0}^{r} z_{0}+\lambda_{0}^{p} \frac{\eta}{\theta} z_{0}\left(\frac{1+\eta}{\eta}-m c_{0}\right)=0 \\
& -\lambda_{0}^{c}\left(2-\frac{1}{R_{0}^{*}}\right)+\lambda_{0}^{b}-\frac{\lambda_{0}^{s}}{\lambda_{0}^{2}} U_{h}\left(c_{0}, h_{0}\right) h_{0}-\lambda_{0}^{p} \beta \mathbb{E}_{0}\left(\frac{\lambda_{1}}{\lambda_{0}^{2}}\left(\Pi_{1}-\bar{\Pi}\right) \Pi_{1}\right)=0 \\
& -\frac{\lambda_{0}^{c} \lambda_{0}}{\left(R_{0}^{*}\right)^{2}}-\lambda_{0}^{b} \beta \mathbb{E}_{0} \frac{\lambda_{1}}{\Pi_{1}}+\beta \mathbb{E}_{0} \frac{\lambda_{1}^{s}}{\Pi_{1}}\left(1-k^{\prime}\left(b_{0}\right)\right) b_{0}=0 \\
& \lambda_{0}^{s}\left[1-k^{\prime}\left(b_{0}\right)\right]-\beta \mathbb{E}_{0} \frac{\lambda_{1}^{s}}{\Pi_{1}}\left\{\left[R_{0}^{*}-\left(R_{0}^{*}-1\right)\left(k^{\prime}\left(b_{0}\right)+b_{0} k^{\prime \prime}\left(b_{0}\right)\right)\right]+k^{\prime}\left(b_{0}\right)\right\}=0 \\
& \frac{\lambda_{0}^{s}}{\Pi_{0}^{2}}\left[R_{-1}^{*}-\left(R_{-1}^{*}-1\right) k^{\prime}\left(b_{-1}\right)\right] b_{-1}+\frac{\lambda_{0}^{s}}{\Pi_{0}^{2}}\left[c_{-1}-k\left(b_{-1}\right)\right]-\theta \lambda_{0}^{r}\left(\Pi_{0}-\bar{\Pi}\right)-\lambda_{0}^{p}\left(2 \Pi_{0}-\bar{\Pi}\right)=0 \\
& \lambda_{0}^{s}=\frac{\eta}{\theta} \lambda_{0}^{p} \\
& U_{c}\left(c_{0}, h_{0}\right)=\lambda_{0}\left(2-\frac{1}{R_{0}^{*}}\right) \\
& \lambda_{0}=\beta R_{0}^{*} \mathbb{E}_{0} \frac{\lambda_{1}}{\Pi_{1}} \\
& c_{0}-k\left(b_{0}\right)+b_{0}+\left(m c_{0} z_{0}+\frac{U_{h}\left(c_{0}, h_{0}\right)}{\lambda_{0}}\right) h_{0}=\frac{c_{-1}-k\left(b_{-1}\right)}{\Pi_{0}}+\frac{\left(R_{-1}^{*}-\left(R_{-1}^{*}-1\right) k^{\prime}\left(b_{-1}\right)\right) b_{-1}}{\Pi_{0}}+g_{0} \\
& z_{0} h_{0}=c_{0}+g_{0}+\frac{\theta}{2}\left(\Pi_{0}-\bar{\Pi}\right)^{2} \\
& \left(\Pi_{0}-\bar{\Pi}\right) \Pi_{0}=\beta \mathbb{E}_{0}\left(\frac{\lambda_{1}}{\lambda_{0}}\left(\Pi_{1}-\bar{\Pi}\right) \Pi_{1}\right)+\frac{\eta}{\theta} z_{0} h_{0}\left(\frac{1+\eta}{\eta}-m c_{0}\right) .
\end{aligned}
$$

where $\lambda_{-1}^{c}=\lambda_{-1}^{b}=\lambda_{-1}^{s}=\lambda_{-1}^{r}=\lambda_{-1}^{p}=0$.

\section{Appendix C. Solving for $\phi$ and $\delta$}

From the Ramsey planner's version of the government budget constraint, we have at steady state

$$
[\bar{c}-k(\bar{b})]\left(1-\bar{\Pi}^{-1}\right)+\bar{b}\left(1-\frac{\left(\bar{R}^{*}-\left(\bar{R}^{*}-1\right) k^{\prime}(\bar{b})\right)}{\bar{\Pi}}\right)+\left(\overline{m c} \bar{z}+\frac{U_{h}(\bar{c}, \bar{h})}{\bar{\lambda}}\right) \bar{h}-s_{g} \bar{z} \bar{h}=0
$$

and given our assumption on functional forms, we have 


$$
U_{h}(\bar{c}, \bar{h})=-\delta /(1-\bar{h}), k(\bar{b})=\phi\left(1-e^{-\frac{\bar{b}}{c}}\right), k^{\prime}(\bar{b})=\frac{\phi}{\bar{c}} e^{-\frac{\bar{b}}{c}} .
$$

Given $\bar{h}$ and $s_{g}$, we can solve for $\bar{c}$ from the resource constraint (18) at steady state. And $\bar{\Pi}, \bar{b}, \bar{R}^{*}$ are known values, while $\bar{\lambda}$ can be solved from the first-order condition $U_{c}(\bar{c}, \bar{h})=1 / \bar{c}=\bar{\lambda}\left(2-1 / \bar{R}^{*}\right)$. Using the optimality condition (26) at steady state, we can calibrate $\phi$ from

$$
k^{\prime}(\bar{b})=\frac{\phi}{\bar{c}} e^{-\frac{\bar{b}}{c}}=\frac{\bar{R}^{*}-\bar{R}}{\bar{R}^{*}-1}
$$

given an estimate of $\bar{R}$. Once all the required values are known, one can solve for $\delta$ from (32).

\section{Appendix D. Computing welfare cost of fluctuations}

In this appendix, we derive the specific log-utility welfare cost of economic fluctuations for a particular economy indexed by some parameter (in this case $\phi$ ), which is conveniently labeled as economy $i$. Expanding the LHS of Eq. (27) and assuming per-period utility of the form $U\left(c_{t}, h_{t}\right)=\ln c_{t}+\delta \ln \left(1-h_{t}\right)$, we have:

$$
(1-\beta) \mathbb{E}_{\sigma_{i}\left(z_{0}, g_{0}\right)}\left\{\sum_{t=0}^{\infty} \beta^{t}\left[\ln \left(1+\Omega_{i}\right)+\ln \left(c_{t}\left[\sigma_{i}\left(z_{0}, g_{0}\right)\right]\right)+\delta \ln \left(1-h_{t}\left[\sigma_{i}\left(z_{0}, g_{0}\right)\right]\right)\right]\right\} .
$$

The RHS of Eq. (27) can also be expanded as

$$
(1-\beta) \sum_{t=0}^{\infty} \beta^{t}\left[\ln \left(\bar{c}_{i}\right)+\delta\left(1-\bar{h}_{i}\right)\right] .
$$

Equating these two infinite series, we have

$$
\begin{aligned}
\ln \left(1+\Omega_{i}\right) & =-(1-\beta) \mathbb{E}_{\sigma_{i}\left(z_{0}, g_{0}\right)}\left\{\sum_{t=0}^{\infty} \beta^{t}\left[\ln \left(\frac{c_{t}\left[\sigma_{i}\left(z_{0}, g_{0}\right)\right]}{\bar{c}_{i}}\right)+\delta \ln \left(\frac{1-h_{t}\left[\sigma_{i}\left(z_{0}, g_{0}\right)\right]}{1-\bar{h}_{i}}\right)\right]\right\} \\
& \approx-(1-\beta) \mathbb{E}_{\sigma_{i}\left(z_{0}, g_{0}\right)}\left\{\sum_{t=0}^{\infty} \beta^{t}\left[\hat{c}_{t}-\left(\frac{\delta \bar{h}_{i}}{1-\bar{h}_{i}}\right) \hat{h}_{t}\right]\right\} .
\end{aligned}
$$

Since there is no closed-form expression for the decision rules of consumption and leisure, to evaluate Eq. (28), we use Monte Carlo simulations to evaluate the integral functions implicit in the expected payoffs. We estimate, for example, the average of (28) by an $\widehat{\Omega}_{i}$ satisfying

$$
\ln \left(1+\widehat{\Omega}_{i}\right)=-(1-\beta) \frac{1}{H} \sum_{n=1}^{H}\left\{\sum_{t=0}^{T} \beta^{t}\left[\hat{c}_{t}\left[\sigma_{i}\left(z_{0, n}, g_{0, n}\right)\right]-\left(\frac{\delta \bar{h}}{1-\bar{h}}\right) \hat{h}_{t}\left[\sigma_{i}\left(z_{0, n}, g_{0, n}\right)\right]\right]\right\},
$$

where the number of shock histories $H$, and, approximating horizon $T$, are very large.

\section{References}

Aiyagari, R., Marcet, A., Sargent, T.J., Seppälä, J., 2002. Optimal taxation without state-contingent debt. Journal of Political Economy 110, $1220-1254$. Atkinson, A.B., Stiglitz, J.E., 1980. Lectures on Public Economics. McGraw-Hill, New York.

Bansal, R., Coleman, W.J., 1996. A Monetary explanation of the equity premium, term premium and risk-free rate puzzles. Journal of Political Economy 104, $1135-1171$.

Calvo, G.A., Guidotti, P.E., 1993. On the flexibility of monetary policy: The case of the optimal inflation tax. Review of Economic Studies 60, 667-687.

Canzoneri, M.B., Cumby, R.E., Diba, B.T., 2007. Euler equations and money market interest-rates: a challenge for monetary policy models. Journal of Monetary Economics 54 (7), 1863-1881.

Canzoneri, M.B., Diba, B.T., 2005. Interest-rate rules and price determinacy: The role of transactions services of bonds. Journal of Monetary Economics 52, $329-343$.

Chari, V.V., Christiano, L.J., Kehoe, P.J., 1991. Optimal fiscal and monetary policy: Some recent results. Journal of Money, Credit and Banking 23, 519-539.

Chari, V.V., Christiano, L.J., Kehoe, P.J., 1995. Policy analysis in business cycle models. In: Cooley, T.F. (Ed.), Frontiers of Business Cycle Research. Princeton University Press, New Jersey, pp. 357-391.

Giovannini, A., Labadie, P., 1991. Asset prices and interest-rates in cash-in advance models. Journal of Political Economy 99 (6), 1215-1251.

Lucas, R.E., 1987. Models of Business Cycles. Basil Blackwell, UK.

Lucas, R.E., Stokey, N., 1983. Optimal fiscal and monetary policy in an economy without capital. Journal of Monetary Economics 12, 55-93.

Patinkin, D., 1965. Money. Interest and prices: An integration of monetary and value theory. MIT Press, Cambridge, MA.

Rotemberg, J.J., 1982. Sticky prices in the united states. Journal of Political Economy 90, 1187-1211.

Schmitt-Grohé, S., Uribe, M., 2004a. Optimal fiscal and monetary policy under sticky prices. Journal of Economic Theory 114, 198-230.

Schmitt-Grohé, S., Uribe, M., 2004b. Solving dynamic general equilibrium models using a second-order approximation to the policy function. Journal of Economic Dynamics and Control 28, 755-775.

Siu, H., 2004. Optimal fiscal and monetary policy with sticky prices. Journal of Monetary Economics 51, 575-607.

Tobin, J., 1965. The interest-elasticity of transactions demand for cash. Review of Economic Studies 38, 241-247.

Weil, P., 1989. The equity premium puzzle and the risk-free rate puzzle. Journal of Monetary Economics 24, 401-421. 